\title{
El flujo de caja libre, operativo y del accionista, los elementos creadores de valor. Los value drivers o inductores de valor corporativos
}

\section{The cash flow free, operational and shareholder, the value creators. The value drivers or corporate value inducers}

\author{
Alberto Rigail Cedeño \\ Pontificia Universidad Católica, Perú \\ Eduardo Jurado Vinueza, Ph.D. Candidate \\ Pontificia Universidad Católica De Perú
}

Autor para correspondencia: ejuradov@pucp.pe; arigail@pucp.pe

Fecha de recepción: 05 de Enero de 2016 - Fecha de aceptación: 15 de Marzo de 2016

\section{Resumen}

El estudio presenta varios módulos que se utilizan para evaluar empresas, y los compara según varios factores como el flujo, operativos, e inductores de valor corporativos.

Palabras Claves: valoración de empresas; flujo de caja libre; inductores de valor corporativos

\begin{abstract}
This study presents various modules that are used for evaluating business and compares them based on factors such as flux, operatives, value drivers, and value inductors.
\end{abstract}

Key words: business evaluation; flux; value drivers 


\section{Introducción}

\section{La valoración de empresas}

Conocer el valor de mercado de una empresa podría plantearse como respuesta a muchas inquietudes del mundo empresarial. Pablo Fernández en su documento de investigación:

Métodos de Valoración de Empresas, describe 9 posibles propósitos de valoración:

1. Operaciones de compraventa, donde la utilidad se relaciona con la determinación del valor máximo que estaría dispuesto a pagar el comprador en relación al valor mínimo que desearía cobrar el vendedor.

2. Valoración de empresas cotizadas en bolsa, para determinar el valor fundamental de sus acciones y así compararlo con el valor real al que se están cotizando en el mercado en función de las expectativas de los inversionistas.

3. Salidas de empresas a cotizar por primera vez en bolsa, con el objetivo de calcular el precio al que deberían negociarse sus acciones en el mercado para tratar de obtener por lo menos su precio justo.

4. Valoración de herencias y testamentos para calcular precios referenciales y poder compararlos con otros activos de características similares.

5. Medición de sistemas de remuneración basados en creación de valor, para cuantificar la obtención de resultados por parte de los directivos evaluados.

6. Identificación y jerarquización de los impulsadores de valor (value drivers), para determinar las variables que le generan valor agregado a la empresa así como aquellas que se lo destruyen.

7. Toma de decisiones estratégicas acerca de la continuidad de la empresa, de tal manera que se pueda identificar si la empresa debe seguir como negocio en marcha o mejor dar por terminado sus operaciones.

8. Planeación estratégica, para identificar lineamientos hacia futuro, determinar qué decisiones tomar sobre productos, nuevos mercados y demás temas relevantes.

9. Procesos de arbitraje y pleitos, como ayuda en decisiones por parte de jueces ante situaciones de conflictos

10. Las razones mencionadas anteriormente han dado origen a la revisión y planteamiento de varios modelos de valoración, los cuales presentan ventajas y desventajas que serán descritos y analizados a continuación. 
Damodaran (2005) considera que en términos generales, hay cuatro enfoques para la valoración. El primero, modelo de flujos de caja descontados que presenta la relación entre el valor de un activo con el valor presente de los flujos de caja futuros esperados de ese activo.

El segundo método de valoración contable y valor de liquidación, que se articula en torno a la valoración de los activos existentes de una empresa, tomando como punto de partida de las estimaciones, al valor contable o valor en libros.

La tercera, la valoración relativa, estima que el valor de un activo puede obtenerse en base a la fijación de precios de los activos «comparables» con respecto a una variable común, como por ejemplo ganancias, flujos de efectivo, el valor contable o de ventas. El último método es el de valoración de contingentes, que utiliza modelos de valoración de opciones para medir el valor de las acciones de acuerdo a sus características, este último es el que se conoce como opciones reales.

Fernández (2008) amplia la clasificación de los modelos y nos presenta seis agrupaciones que van desde las más discutidas pero que aún pueden ser utilizadas por dueños de empresas tradicionales, así como las más novedosas herramientas coincidiendo con Damodaran (2005) en el planteamiento de opciones reales como alternativa de valoración corporativa.

A continuación se presenta la clasificación de los diferentes modelos de valoración según consta en la tercera edición del Libro "Valoración de Empresas" de Pablo Fernández (Fernández, Valoración de Empresas, 1998):

Tabla 1: Principales métodos de valoración

\begin{tabular}{|c|c|c|c|c|c|}
\hline BALANCE & $\begin{array}{c}\text { CUENTA DE } \\
\text { RESULTAD } \\
\text { OS }\end{array}$ & $\begin{array}{c}\text { MIXTOS } \\
\text { (GOODWIL } \\
\text { L) }\end{array}$ & $\begin{array}{c}\text { DESCUENTO } \\
\text { DE FLUJOS }\end{array}$ & $\begin{array}{l}\text { CREACIÓN } \\
\text { DE VALOR }\end{array}$ & OPCIONES \\
\hline $\begin{array}{l}\text { Valor contable } \\
\text { Valor contable } \\
\text { ajustado Valor } \\
\text { de liquidación } \\
\text { Valor } \\
\text { sustancial }\end{array}$ & $\begin{array}{c}\text { Múltiplos de: } \\
\text { Beneficios } \\
\text { PER } \\
\text { Ventas }\end{array}$ & $\begin{array}{l}\text { Clásico } \\
\text { Unión de } \\
\text { expertos } \\
\text { Contables } \\
\text { europeos } \\
\text { Renta } \\
\text { abreviada }\end{array}$ & $\begin{array}{c}\text { Free cash flow } \\
\text { Cash flow } \\
\text { acciones } \\
\text { Dividendos } \\
\text { Capital cash flow }\end{array}$ & $\begin{array}{c}\text { EVA } \\
\text { Beneficio } \\
\text { Económico } \\
\text { Cash value } \\
\text { added } \\
\text { CFROI }\end{array}$ & $\begin{array}{l}\text { Black y Scholes } \\
\text { Opción de } \\
\text { invertir } \\
\text { Ampliar el } \\
\text { proyecto Aplazar } \\
\text { la } \\
\text { inversión }\end{array}$ \\
\hline $\begin{array}{l}\text { Activo } \\
\text { neto } \\
\text { real }\end{array}$ & $\begin{array}{c}\text { Ebitda } \\
\text { Otros } \\
\text { múltiplos }\end{array}$ & Otros & APV & & $\begin{array}{c}\text { Usos } \\
\text { alternativo } \\
\mathrm{s}\end{array}$ \\
\hline
\end{tabular}

Los métodos basados en el Balance consideran el valor de la empresa en función de información estática en determinado momento del tiempo, considerando su valor de mercado acorde a su valor contable o valor en libros. 
Dado lo anterior la principal crítica que se les realiza en que no consideran criterios como oportunidades de crecimiento, expectativas del mercado con respecto a creación de nuevos productos y valor del dinero en el tiempo, entre otros.

Estos métodos están enfocados en cuánto vale el patrimonio. Son métodos tradicionales, es una perspectiva estática. El Valor contable es la diferencia entre el activo total y el pasivo exigible.

Es el valor reflejado en el Balance, de acuerdo a normas contables. Es el valor en libro del capital más reservas.

Se puede ajustar en cuyo caso es el valor contable ajustado. En tal caso: en las deudas, deben descontarse las incobrables, los inventarios deben ajustare se a lo real y, los activos ponerlos en valor real, según expertos. Es decir apegar a la realidad lo más posible el balance.

El valor de liquidación es el valor mínimo de una empresa. Valor de liquidación, cuando se prevé liquidar una empresa. Comprende el Capital y reservas menos la liquidación de empleados Valor sustancial es otra forma de valor que considera el valor si se quisiera poner a funcionar una empresa en las mismas condiciones.

Los métodos basados en la cuenta de resultados, se fundamentan en la capacidad de predecir valor de mercado de las empresas en función de cómo éstas están siendo cotizadas en función de su nivel de ventas, ingresos netos, razón precio a beneficios (PER), utilidad antes de intereses, impuestos, depreciación y amortización (EBITDA), entre otros parámetros.

Estos métodos creen haber encontrado patrones de comportamiento entre los indicadores mencionados y la fijación del precio de sus acciones, permitiéndoles estimar el valor total del patrimonio de la empresa. La gran crítica a estos modelos es que se fundamentan en que "los mercados financieros tienen memoria", es decir repiten siempre un mismo comportamiento, lo cual en la práctica no ocurre, pues nada es estático en el mundo financiero ni sigue un patrón constante a través del tiempo, lo que haría fallar el poder predictivo de estos modelos.

Una de las herramientas para este método puede ser el uso de ratios. Un ratio es el resultado de dividir dos magnitudes conexas. Comparan el valor de mercado vs el valor contable.

A continuación la tabla 2 plantea algunos ratios usados según diferentes sectores económicos: 
Tabla 2: Ratios usados según sectores

\begin{tabular}{|l|l|l|}
\hline Sector & Subsector & Múltiplos más utilizados \\
\hline Automotor & Fabricantes, componentes & P/S, P/CE \\
\hline Bancos & & P/BV \\
\hline Materiales & Papel, químicos, minería & P/BV, EV/EBITDA \\
\hline Servicios & & EV/EBITDA \\
\hline Sanidad & & PER, EV/EBITDA \\
\hline Transporte & Aéreo, terrestre & P/S, EV/EBITDA \\
\hline Inmobiliarias & & $\begin{array}{l}\text { P/FAD, } \\
\text { EV/EBITDA }\end{array}$ \\
\hline & & \\
\hline
\end{tabular}

El más popular de los ratios financieros es, sin duda, la relación precio/beneficio (Price earnig ratio), comúnmente conocida como (PER) que el precio dividido para el beneficio por acción. El dividendo es un pago que se hace al accionista en función de una rentabilidad exigida. Es la remuneración de los accionistas (ecuación 1).

$$
\frac{\text { Precio }}{\text { Ventas }}=\left(\frac{\text { Precio }}{\text { Beneficios }}\right) *\left(\frac{\text { Beneficios }}{\text { Precio }}\right)=\text { PER } * \text { Rentabilidad sobre ventas }(1)
$$

La ventaja del método ejemplificado es la sencillez de su utilización. La desventaja radica en las simplificaciones que se cometen. Según Fernández (2001) en sectores muy maduros, cercanos al oligopolio, donde los competidores no dejan espacios para la entrada de nuevos miembros y la rivalidad es menor, parece razonable que las empresas se parezcan mucho entre sí, en lo que se refiere a la relación entre lo que ganan y el precio de las acciones. En estos casos, la utilización del ratio PER está justificada mientras se considere que, en el futuro, se mantendrá el statu quo.

Los métodos mixtos (Goodwill, una de sus traducciones Fondo de Comercio), describe la existencia de una serie de intangibles que le dan valor agregado al valor contable, en función del posicionamiento de la empresa, su trayectoria, valoración de marca, perspectivas de crecimiento, entre otros elementos.

Existen diferentes metodologías propuestas y todas están encaminadas a cuantificar estos intangibles, valoración que será dinámica dependiendo de la etapa en la que se realice la valoración. El Good Will es un anglicismo que significa o hace referencia al buen nombre de una empresa, producto, servicio, persona, etc. El buen nombre o prestigio que tiene una empresa o establecimiento frente a terceros, es un activo de gran valor, puesto que ese buen nombre le permite obtener clientes, proveedores, créditos, etc.

El buen nombre, coloca a una empresa en posición ventajosa frente a la competencia, facilitándole su incursión o sostenimiento en el mercado. Permitiéndole también, mejores ventas y en muchos casos, a precios un poco más altos, puesto que el consumidor siempre está dispuesto pagar un poco más por tener un producto de "marca", lo que indudablemente le permite tener una mejor rentabilidad. Good Will es el valor de lo inmaterial que no aparece reflejado en los 
balances. Lo interesante es que refleja las confecciones con los clientes, la reputación y factores similares. No obstante el problema es que no existe unanimidad ideológica.

Los modelos de flujos de caja descontados, son de los más usados en su categoría, debido a que pueden ser vistos como la sumatoria de los puntos fuertes de cada una de las clasificaciones anteriores.

Primero toman en consideración los estados financieros de años anteriores, partiendo de un análisis histórico de sus principales cuentas, relacionándolo posteriormente con las expectativas de la empresa a largo plazo, las estrategias que planean implementarse así como información existente sobre condiciones macroeconómicas que pudiesen influir en la obtención de resultados futuros de la empresa.

Los métodos de creación de valor tienen como principal exponente al EVA (por sus siglas en inglés o VEA que representa Valor Económico Agregado. Este método fue creado por la consultora Stern Stewart \& Co. para ser utilizado en la valoración de empresas y su objetivo "es calcular la rentabilidad contra el costo de capital sobre un capital inicial, que al ser proyectado y descontado al valor actual, permite determinar el valor de mercado que la dirección superior ha generado o destruido del capital utilizado" (Stewart, 2000).

Por último aparece la categoría más reciente de valoración: Opciones reales, como una categoría que plantea alternativas para determinar el valor de mercado de la empresa en diferentes etapas de su situación económica y financiera, considerando opciones de abandono, aplazamiento de proyectos, entre otras decisiones críticas para la empresa.

Milla Gutiérrez y Martínez Pedrós en su libro electrónico "Valoración de Empresas por Flujos de caja descontados ${ }^{1}$ " describen que una clasificación de los principales modelos de valoración basados en el descuento de flujos de caja sería la siguiente:

- Modelos basados en el descuento de dividendos (DDM).

- Modelos basados en el descuento de flujos de caja libre (DFCF).

- Modelos basados en el descuento del valor económico añadido (EVA).

- Modelos basados en el descuento de la renta residual (RIM).

Dependiendo del investigador se pueden seguir detallando diferentes clasificaciones sin embargo, la gran mayoría coincide en el uso de flujos de caja descontados como una de las aplicaciones más comunes.

Para empresas que cotizan en la bolsa de valores, una gran herramienta podría ser el modelo de Gordon, uno de los métodos más utilizado por los administradores y gerentes financieros para evaluar el valor teórico de la empresa. El modelo parte de la idea de que la política de dividendos sí afecta al valor de las acciones de la empresa, para ello, acepta que el

\footnotetext{
${ }^{1} \mathrm{Http} / / /$ Www.Altair-Consultores.Com/Images/Stories/Publicaciones/Libro_Valoracion.Pdf
} 
valor de la empresa puede ser calculado como el valor actual de todos los dividendos futuros que se paguen durante la vida de la empresa, que se supone sea infinita.

El Modelo de Gordon parte de la situación de una empresa en el instante actual: $\mathrm{t}=0$, e intenta averiguar qué destino debe darse, en el contexto de un horizonte de planificación perpetuo, al resultado neto después de impuestos; esto es, si se debe repartir en forma de dividendos o si es mejor retenerlo en el interior de la empresa para financiar futuros procesos de inversión.

La expresión básica del Modelo de Gordon, para calcular el valor de la empresa en un momento determinado, está dado por la ecuación (2):

$$
P=\frac{\operatorname{Div}(1+g)}{(1+R e)^{!}}+\frac{D i v !(1+g) !}{(1+R e)^{!}}+\cdots+\frac{\operatorname{Div}(1+g) !}{(1+R g) !}
$$

Donde:

P: Precio por acción de acciones comunes en el mercado donde cotice la empresa

Div0: Dividendo pagado por la empresa en el periodo cero. g: Tasa de crecimiento a la que se espera crezca la empresa en función de su reinversión de utilidades.

Re: Tasa de rendimiento esperada por los accionistas.

El valor de las acciones de esta empresa en el mercado, inmediatamente después de repartir en el instante inicial el dividendo DIVo, se obtendrá, capitalizando la corriente futura de dividendos a la tasa $R e$ del accionista, tasa que representa la rentabilidad que se podría obtener en el mercado financiero de manera alternativa para inversiones similares.

La ecuación anterior adolece de una limitación, para que pueda ser calculada deberá conocerse el horizonte de inversión, el mismo que en la práctica es imposible de saber, debido a que la tenencia de la acción dependerá de varios factores, que van desde las noticias positivas o negativas sobre la empresa que la ha emitido hasta las necesidades de liquidez del accionista que puedan llevar a venderla antes del tiempo que tenía planificado tenerla originalmente.

Es por esto que en la práctica, la ecuación (2) se ha utiliza de acuerdo a la ecuación (3) que representa una perpetuidad que está relacionado con el desconocimiento del tiempo que se tendrá las acciones.

$$
P=\frac{D I V !(1+g)}{R e-g}
$$

La ecuación (3) refleja que el valor actual de la acción es igual al dividendo esperado al final del período dividido por la tasa de retorno requerida por los accionistas menos la tasa de crecimiento de las ganancias.

Cualquier empresa que aumente la tasa de rendimiento de sus inversiones, $r$, conseguirá aumentar el valor de sus acciones. Los cambios en la tasa de retención de beneficios afectan tanto a la cuantía del dividendo como a la tasa de crecimiento de las ganancias. 
Una asunción importante de este modelo es que asume que los dividendos y las utilidades crecen en igual proporción. Los tratadistas financieros consideran esta suposición es cierta solamente en casos en que una empresa distribuya anualmente un porcentaje fijo de sus utilidades, es decir una razón de pagos fijos. Si se supone una tasa de crecimiento constante se obtiene la expresión del valor teórico de una acción de capital.

Otro problema al utilizar este modelo está en la dificultad de calcular la tasa de capitalización del accionista $(\mathrm{Re})$ y las utilidades con su tasa de crecimiento. Un mecanismo habitual es calcular la tasa de capitalización del capital utilizando los rendimientos por utilidades (inversa de la razón precio-utilidades), es decir, las utilidades por acción divididas entre el precio en el mercado por acción.

Otra manera de calcular dicha tasa es sustituir los datos del dividendo histórico, precios de la acción, tasas de crecimiento y utilizando la tasa de capitalización con base histórica que resulte de la división del dividendo histórico para el precio de las acciones.

Luego, la tasa de crecimiento del dividendo puede encontrarse utilizando los valores históricos del dividendo por acción para calcular la tasa compuesta de crecimiento anual. El Modelo de Gordon que capitaliza los rendimientos futuros de la empresa durante una vida supuestamente infinita, es el método más correcto teóricamente ya que considera a la empresa como un negocio en marcha y no utiliza valores de activos o precios en el mercado como anexos en el proceso de valuación. En lugar de ello, supone que el valor de la empresa es igual al valor descontado de todos los rendimientos futuros.

Otro modelo de valoración es el Modelo de Lintner, cuyo autor realizó este modelo a través de una serie de entrevistas con directivos, llegó a la conclusión de que la mayoría de las empresas tienen unas tasas "marco" (de referencia) de reparto de dividendos a largo plazo a las que suelen ajustarse. Todo ello porque dichos ejecutivos partían de la base de que los accionistas tenían derecho a una parte razonable de las utilidades de la empresa, así como que preferían un crecimiento constante de los dividendos, esto es, aunque las utilidades creciesen fuertemente, los dividendos crecerían un ritmo más lento, con el objeto de evitar recortes de los mismos en los años en los que la utilidad fuese menor del esperado.

Así, una empresa que permanece siempre fiel a sus razones financieras objetivo de pago de dividendos siempre tendrá que cambiar su cuantía si cambian las utilidades o ganancias. Sin embargo, según los aspectos anteriores, los directivos creen que los accionistas prefieren una progresión estable de los dividendos, y por tanto, si las circunstancias permiten garantizar un gran incremento de los dividendos, no ofrecerán más que parte del nivel al que tiende el ratio objetivo.

La discusión acerca si la decisión de dividendos transmite o no información al mercado sigue siendo uno de los temas más controvertidos dentro de las finanzas empresariales. Al respecto, las investigaciones empíricas realizadas durante los últimos años no sólo son concluyentes sino que resultan claramente contradictorias. Existen dos posiciones doctrinales diferentes: la hipótesis de neutralidad de los dividendos y la hipótesis de relevancia de los mismos. 
Son múltiples los modelos teóricos que explican la relación entre la política de dividendos y el valor de las acciones a partir de la situación informativa en el mercado, y de un amplio abanico de soluciones.

Uno de los planteamientos es que los dividendos poseen un contenido informativo y la posibilidad de que la política de dividendos puede ser tomada en cuenta por los inversionistas al momento de decidir sobre retener acciones o comprarlas por el efecto señales que puede transmitir al mercado con respecto a la capacidad de la empresa para generar flujos futuros en función de las expectativas de crecimiento que sea o no y que serán visibles en función de la política de reinversión o de pago de dividendos que mantenga.

Dentro de los defensores de la política de dividendos, destacan los estudios de Albouy y Durand entre otros. Estos estudios son sólo una muestra de todos los que se han realizado desde que Miller y Modigliani lanzaron su hipótesis de la irrelevancia de la política de dividendos. A lo largo de todos ellos se ha demostrado que los investigadores han sido incapaces de aislar el efecto de la política de dividendos sobre los precios de las acciones.

Aunque sobre horizontes temporales bastante grandes parece detectarse una ligera ventaja de las empresas que reparten dividendos bajos, las cuales parecen conseguir unos mayores precios relativos para sus acciones. En un trabajo de 1971, Ross demostró que un incremento de los dividendos pagados (o en el uso de deuda) de empresas norteamericanas, puede presentar una señal confiable y precisa para el mercado sobre la mejoría de las perspectivas de la empresa.

En todo caso, a pesar de todos los argumentos no se detecta un camino por el cual la empresa pueda hacer variar el precio de sus acciones a través de la política de dividendos acompañados de que la señal que pueda lanzar al mercado la empresa utilizando la política de dividendos para favorecerla, puede ser una señal muy costosa si es que las expectativas no se cumplen con un pago de dividendos más altos en el futuro.

Debido a la poca capacidad de los investigadores para conectar la rentabilidad sobre los dividendos con la rentabilidad de los activos financieros ha relegado a la política de dividendos a la posición que le corresponde en la jerarquía de las decisiones empresariales (de estrategia corporativa), es decir por debajo de las decisiones de inversión que se consideran son las que crean valor realmente para la empresa.

Por lo tanto, la gerencia de una empresa no está justificada en renunciar a inversiones rentables para satisfacer las posibles demandas de los inversores en orden a un aumento de los dividendos. En efecto, si los dividendos influyen sobre los precios de las acciones será, probablemente, debido a que los inversores desean minimizar o diferir el pago de impuestos, así como minimizar los costos de agencia.

Pues, si la teoría de las expectativas se cumple, permitirá a la directiva de la empresa evitar sorprender a los accionistas cuando se produzca la decisión sobre los dividendos. Igualmente, la política de dividendos puede ser tratada como un residuo a largo plazo después de que la gerencia estime las necesidades de inversión a largo plazo. Ello, a su vez, permitiría establecer una tasa de reparto de beneficios "marco" sobre la que ceñirse. 


\section{Modelos de valoración de empresas por flujos de caja descontados: Revisión de literatura}

Miller y Modigliani (1958) son considerados los autores que vinieron a generar la discusión acerca de la necesidad de clarificar el valor de Mercado de la empresa, que hasta ese momento se relacionaba con la conformación de una estructura de capital óptima que llevara a maximizar su riqueza en el mercado de las acciones de la empresa.

En esos años, los economistas financieros compartían la idea de que existía una estructura óptima de capital para la empresa: aquella que minimizase su coste de capital y, por ende, maximizara su valor de mercado.

Esta creencia generalizada se diluyó cuando Modigliani y Miller demostraron que el valor de la empresa, el coste del capital y la rentabilidad requerida de los proyectos de inversión es independiente de su estructura de capital, estableciendo así una completa separación de las decisiones empresariales de inversión y financiación: El valor de la empresa depende únicamente de la capacidad de su cartera de proyectos para generar renta, no de los títulos que la empresa emite para financiar sus inversiones (Palenzuela \& Herrero, 2008).

Lo anterior "era una forma de decir a los directores financieros que no intentasen aumentar la riqueza de sus accionistas ajustando la razón de deuda de la empresa de la empresa, ya que ese tipo de políticas no surte efecto alguno sobre la creación de valor. Por añadidura, no habría razones para preferir una determinada estructura de capital frente a otras. Más aún, la mejor estructura de capital sería la que en cada momento soporta las inversiones y operaciones de la empresa".

Considerando lo antes expuesto, modelos de valoración que consideran el valor agregado generado por las decisiones de la gerencia con respecto al futuro de la empresa tienen sentido, es por este motivo que se procede a presentar información relacionada con los métodos que utilizan el descuento de flujos de caja para determinar el valor de mercado de las empresas.

Pereira (2008) presenta un pequeño ejemplo de ilustración para discutir sobre el criterio de proyección y generación de flujos con valor agregado: "Un paquete de activos vale según su capacidad de generar flujos de fondos, y es por ello que tendrá diferentes valores dependiendo de quién lo utilice.

Los flujos serán generados por el uso comercial e industrial de esos activos en el contexto del negocio, solamente si el flujo de fondos generado por ellos es superior al flujo generado en un uso alternativo, por ejemplo la venta a valores de mercado. Así, si una empresa tiene un vehículo Mercedes Benz súper sport último modelo, y nada le prohíbe emplearlo como vehículo para entregar pizza en una empresa de delivery de comida, es muy probable que el flujo de fondos generado por ese auto sea muy inferior que si se utiliza como transporte de pasajeros de lujo, e incluso inferior a su valor residual de venderlo en el mercado.

Sin embargo, el dueño del auto posee la libertad de emplearlo de la manera más lucrativa, aunque para delivery de pizza sea mucho más barato y tal vez genere un flujo de fondos similar el emplear una moto de reparto". 
Con el ejemplo se pretende empezar debatiendo la diferencia entre valor y precio. Valor es la asignación máxima de pago por parte del potencial comprador en base a las características y a lo que espera recibir del activo que está pensando adquirir, mientras que el valor para el potencial vendedor es la cantidad mínima que está dispuesta a recibir basado en las características del activo que está entregando y por lo tanto de los flujos de caja que dejaría de obtener al deshacerse del activo.

Precio por otro lado, es el valor final al que comprador y vendedor logran ponerse de acuerdo en función de sus expectativas sobre la negociación que están realizando, es decir precio es el valor al que se cierra la negociación. Los métodos de valoración independientemente de su clasificación, buscan dar herramientas para determinar ese precio que parte de la valoración que tanto compradores y vendedores hayan estimado y consideren sea representativo del activo que están intercambiando y de lo que representa para cada uno de ellos.

Cuando el activo en cuestión es una empresa, el valor que se le asigne dependerá de muchos factores como son sus expectativas de crecimiento, posicionamiento en el mercado, capacidad de la gerencia para obtención de resultados, imagen corporativa, buenas prácticas empresariales y demás características que contribuyan a la maximización de los flujos de caja que se espera se produzcan a futuro. requisitos:

Según López Lubian y De Luna Butz (2002) los flujos de caja cumplen los siguientes

- Constituyen un movimiento de tesorería

- Son incrementales, es decir se producen si solo se lleva a cabo la decisión.

- Son netos de impuestos.

Para estos autores, el flujo de caja Libre FCF es uno de los modelos de valoración de la empresa.

Un modelo es una herramienta matemática, compuesta por una o varias ecuaciones analíticas, que representa de forma general situaciones complejas. Variantes o desarrollos del modelo, son variaciones efectuadas para incorporar las características específicas del activo valorado, y la información disponible en el modelo general.

Un método, proporciona una guía de actuación a la hora de recoger y manipular los datos necesarios para alimentar el modelo, para la interpretación de resultados, y para el establecimiento de reglas de decisión basadas en estos últimos. El Flujo de Caja Libre es un modelo para valorar la empresa.

De forma genérica puede considerarse la valoración como el proceso mediante el cual se obtiene una medición homogénea de los elementos que constituyen el patrimonio de una empresa o una medición de su actividad, de su potencialidad o de cualquier otra característica de la misma que interese cuantificar. 
Es cada vez más utilizado el descuento de flujos de fondos (cash flows) que considera a la empresa un ente generador de fondos. Los métodos de cash flows determinan el valor de una empresa a través de la estimación de flujos de dinero, para luego descontarlos a una tasa de descuento apropiada.

El valor de las acciones de una empresa -suponiendo su continuidad- proviene de la capacidad de la misma para generar flujos para los propietarios de las acciones. Para este método las empresas deben tener una expectativa de continuidad.

Fernández (2001) cita textualmente a Irving Fisher ${ }^{2}$ para explicar la relación entre el valor de los activos (a los que denominaba bienes de capital) y las rentas que éstos producen:

«Parece que la renta tiene que derivarse del capital y, en cierto sentido, es así. La renta se deriva de los bienes de capital. Pero el valor de la renta no deriva del valor de los bienes de capital. Al contrario, el valor del capital deriva del valor de la renta. (...) Hasta que no sepamos cuánta renta derivará de un bien de capital no podremos hacer una valoración de éste. Es verdad que la cosecha de trigo deriva de la tierra que lo produce, pero el valor de la cosecha no depende del valor de la tierra. Por el contrario, el valor de la tierra depende del valor esperado de sus cosechas.»

Esta idea de Fisher es la que se aplica diariamente para calcular el valor de los activos que se intercambian en los mercados de renta fija.

El valor actual del dinero que produzca en el futuro es la suma de todas las cantidades de dinero que se espera recibir, descontadas a su coste de oportunidad, que es el tipo de interés de mercado.

La expresión matemática de este razonamiento es:

$$
\sum_{t=1}^{t=n} \frac{D_{t}}{(1+r)^{t}}
$$

Donde $\mathrm{D}$ es el dinero que se espera recibir en cada periodo $t, r$ es el tipo de interés de mercado para activos del mimo riesgo y t el momento en que se espera que el activo produzca dinero. Este concepto de valor es aplicable a otros activos financieros, como las acciones.

Milla y Martínez plantean que la valoración de una empresa por el método de los flujos de caja descontados (DCF, por sus siglas en inglés) parte de una serie de premisas comunes con la literatura tradicional de análisis de inversiones, que resumen de la siguiente forma:

a) El valor depende solamente de lo que se espera ocurra en el futuro con el bien o servicio que se pretende valorar y de las expectativas existentes. Por lo tanto, el valor intrínseco o teórico de cualquier empresa depende de los flujos de caja futuros que se estime generará, es decir, de sus expectativas.

\footnotetext{
${ }^{2}$ Irving Fisher (1867-1947) es autor de La Teoría del Interés (1930)
} 
b) El problema del futuro es la incertidumbre existente, así que cualquier valoración de hechos futuros debe tener en cuenta el factor riesgo.

c) Desde hace bastantes décadas, el criterio de valor se utiliza sistemáticamente en la toma de decisiones de negocio y, en concreto, en la evaluación de inversiones. En este sentido, el valor actual neto (VAN) de un proyecto que mide el valor que se espera que cree su ejecución, es un criterio financiero de evaluación utilizado ampliamente por las empresas.

d) El método aplicable a cualquier empresa o activo para estimar su valor consiste en calcular el valor actualizado de las rentas monetarias futuras que se prevé generará para su propietario.

e) Este método, conocido como "descuento de flujos", fue introducido por los premios Nobel Modigliani y Miller en 1961. La dificultad de este método de valoración nace de las limitaciones para realizar unas previsiones razonables de los flujos de caja futuros y de la imprecisión para determinar la tasa de descuento para calcular su valor actual.

f) El valor creado para el accionista se basará, al igual que hace el análisis de inversiones, en el incremento del flujo de efectivo esperado por los accionistas, que es más tangible que el beneficio. El inversor invierte dinero y lo que le interesa es el dinero que va a recibir a cambio.

Los criterios anteriores son utilizados para realizar un pronóstico detallado al momento de elaborar los flujos de caja proyectados, que constituyen la herramienta principal de los modelos de flujos de caja descontados. Los flujos de caja son el reflejo de la evolución de cada una de las cuentas de las empresas y pretenden reflejar las verdaderas entradas y salidas de dinero en efectivo para determinar los montos más aproximados con los que contaría una empresa para gestionar y obtener recursos para sus inversionistas.

En los métodos de valoración por flujos de caja descontados adicionalmente se necesita determinar una tasa de descuento apropiada que refleje el valor del dinero en el tiempo, el costo de oportunidad de los inversionistas de la empresa, el riesgo de inversión acorde al horizonte de planeación, en fin, la incertidumbre de invertir a largo plazo y de que los resultados no se den acorde a la inversión (compra) que se esté realizando por factores tanto microeconómicos (que no se alcancen las sinergias esperadas, pérdida de participación de mercado, presencia de productos sustitutos competitivos, entre otros) o factores macroeconómicos (niveles altos de inflación que incremente costos de materias primas, altas tasas de interés que encarezcan el financiamiento vía deuda, etc.).

Romero (2010) en su libro Principios de Contabilidad define "Negocio en marcha" como el principio de contabilidad generalmente aceptado que plantea la naturaleza de las empresas, de las que se conoce la fecha del inicio de sus operaciones pero no así su fecha de término, solo se parte de que una empresa estará en el mercado mientras le sea rentable continuar operando por lo que muchos estudios financieros parten del supuesto de perpetuidad como horizonte temporal de valoración corporativa. 
Los modelos de valoración por descuento de flujos de fondos, basados en los tres antecedentes mencionados plantean la ecuación (5) como común para la valoración:

$$
V E=\frac{F C_{!}}{(1+R) !}+\frac{F C !}{(1+R) !}+\cdots+\frac{F C !+V R !}{(1+R) !}
$$

Siendo:

VE: Valor de mercado de la empresa proyectado según el modelo.

FC: El flujo de caja proyectado para cada uno de los periodos desde el primero hasta el periodo "n" (tiempo finito del pronóstico financiero, generalmente 5 años).

R: tasa de descuento, costo de oportunidad del inversionista, medida de riesgo de la inversión. VR: Valor residual de la empresa (valor de la perpetuidad de la empresa considerando que al ser negocio en marcha se desconoce el tiempo que permanecerá en el mercando generando flujos de caja).

Calculo del valor residual: El cálculo del Valor Residual (ecuación 6) se estima en función del último flujo de caja proyectado con tiempo finito, asumiendo que de ahí en adelante la empresa crecerá a una tasa constante en función de sus perspectivas futuras y estrategias aplicadas. La ecuación para calcular el Valor Residual sería la siguiente:

$$
V R-\frac{F C_{!}(1+g)}{(R-g)}-\frac{F C_{1 ! !}}{R-\square}
$$

La novedad de la ecuación estaría dada por la variable "g" que representa el gradiente geométrico, es decir porcentaje de crecimiento de la empresa, el cual podría mantenerse constante asumiendo un crecimiento igual en el largo plazo. El concepto económico de la perpetuidad está relacionado con el principio de negocio en marcha, asumiendo que la empresa crecerá a la misma tasa del periodo $n+1$ en adelante. Las perpetuidades son anualidades indefinidas de las que se conoce donde inician pero no donde terminan, son consideradas inversiones permanentes ${ }^{3}$.

\section{El flujo de caja libre FCF, operativo y del accionista}

Damodaran (2001) plantea una versión intermedia, considerando que las etapas de crecimiento de las empresas no tienen que ser constantes a través del tiempo, proponiendo que se segmenten en diferentes etapas que reflejen flujos de caja de periodos de consolidación en el mercado ya que una empresa no necesariamente crecerá por siempre por efectos de aparición de nuevos competidores, pérdida de competitividad del mercado o incluso término de la vida útil del producto que ofrece.

Se procederá a analizar la naturaleza de cada uno de los principales flujos de valoración que se consideran para evaluar a la empresa desde sus diferentes actores y considerando diferentes creadores de valor relacionados con el financiamiento vía deuda que da origen además

\footnotetext{
${ }^{3}$ Blank, L., \& Tarquin, A. (2002). Ingeniería Económica. México D.F.: McGraw Hill.
} 
de riesgos por temas de incumplimiento financiero a beneficios relacionados con la disminución del pago de impuestos, es decir escudos fiscales.

En la tabla 3 se aprecia los flujos de caja de los accionistas (dueños del capital propio de la empresa), acreedores (dueños de los pasivos de la empresa considerando aquellos que poseen costos financieros para la misma, es decir aquella deudas que generan pagos de intereses), flujo de caja libre para la empresa (producto de sus operaciones, de la razón de ser del negocio) y flujo de caja del capital (considerando el efecto en el pago de impuestos por la forma de financiamiento de la empresa, es decir su estructura de capital). ${ }^{4}$

\section{Tabla 3}

\section{Flujos De Fondos Tasa De Descuento Apropiada}

\begin{tabular}{cllll}
\hline \multicolumn{3}{c}{ FLUJOS DE FONDOS } & & TASA DE DESCUENTO APROPIADA \\
\hline FCac & $\begin{array}{l}\text { Flujo de caja para } \\
\text { los accionistas }\end{array}$ & Re & Tasa de rendimiento de los accionistas \\
FCd & Flujo de caja para la deuda & Rd & Tasa de rendimiento de los acreedores \\
FCF & $\begin{array}{l}\text { Flujo de caja libre (Free cash } \\
\text { flow) }\end{array}$ & CCPP/ WACC & $\begin{array}{l}\text { Costo de capital promedio ponderado } \\
\text { (Weighted average cost of capital) }\end{array}$ \\
FCC & $\begin{array}{l}\text { Flujo de caja del capital } \\
\text { (Capital cash flow) }\end{array}$ & $\begin{array}{l}\text { CCPP } \\
\text { de impuestos) }\end{array}$ & $\begin{array}{l}\text { Tasa de descuento de la empresa sin uso de } \\
\text { escudos fiscales. }\end{array}$
\end{tabular}

\section{Fuente: (Fernández, Métodos de Valoración de Empresas, 2008) Elaborado por: Los autores}

En la tabla 3, también se presenta las diferentes tasas de interés a las que serán descontados los flujos de caja dependiendo de la información que se esté buscando. Las tasas de interés reflejan el costo de oportunidad del uso del dinero por cada uno de los inversionistas de la empresa así como del negocio mismo según su estructura de capital.

flow

Pereyra (2008) menciona que el Flujo de Caja Libre conocido en inglés como free cash

(FCF), corresponde al flujo de fondos operativos de una empresa, sin considerar el financiamiento de la misma, aunque si después de impuestos. Se refiere así al sobrante que quedará en la empresa luego de haber cubierto las necesidades operativas de fondos, las inversiones o desinversiones de ésta y al no haber deuda por lo que se asume que tampoco existirá una carga financiera (gastos por intereses).

\footnotetext{
${ }^{4} \mathrm{La}$ forma como se financia una empresa es conocida como "Estructura de Capital", la división entre recursos propios (patrimonio) y recursos de terceros (acredores), indicando el porcentaje de participación de cada uno de los inversionistas de la empresa.
} 


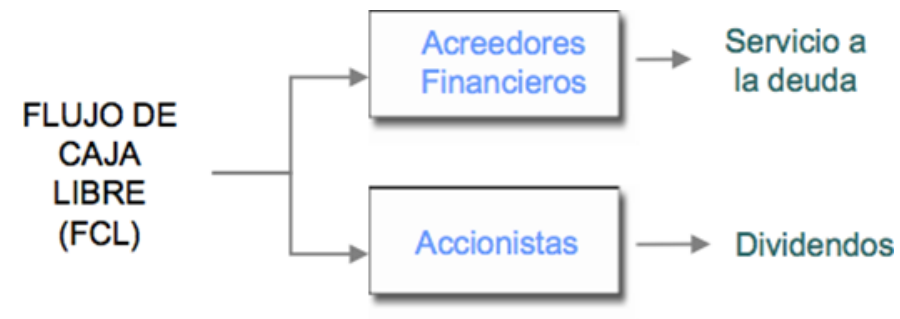

\section{Balance General}

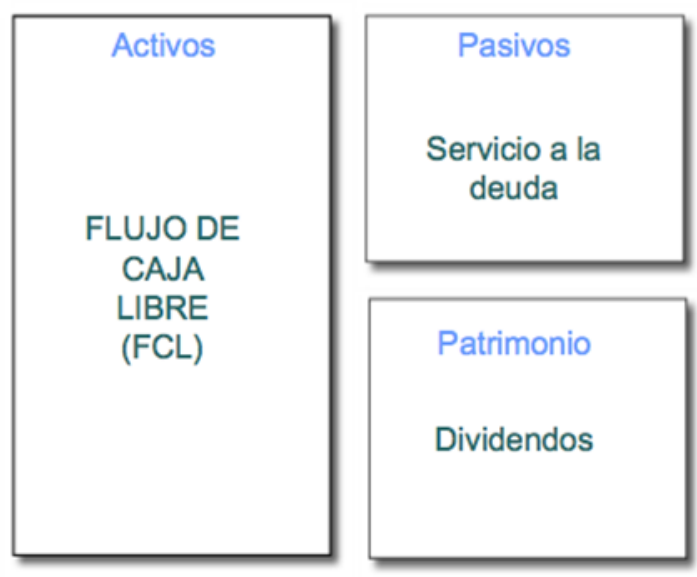

Figura 1

Para determinar el FCF, se procederá de un modo semejante al presupuesto de tesorería, con la diferencia de que se proyectarán los flujos realizados únicamente en efectivo (es decir que se excluyen los conceptos temporales de devengamiento contable y costos de oportunidad, valores que no representan salidas de efectivo sino solamente ajustes contables para reflejar la operación del negocio), y se procurará eliminar la mayor cantidad posible de subjetividades a la hora de determinar el beneficio neto (identificación de ingresos y asignación de costos y gastos en función de proyecciones lo más pegadas a la realidad del macro y micro entorno de la empresa).

Para entender mejor la conformación del FCF se procede a examinar el concepto de Necesidades Operativas de Fondos (NOF) que se refiere a los recursos que necesita financiar la empresa para llevar a cabo su operación. En inglés es conocido como working capital requirements y agrupa en primera instancia los conceptos circulantes por un lado y los no circulantes por otro.

Los activos circulantes representan los recursos que la empresa espera transformar en dinero dentro del ciclo operativo que suele venir de la mano con el periodo contable, es decir un año. El orden de las cuentas al interior de los activos circulantes se establece dada la rapidez con las que las mismas pueden convertirse en dinero en efectivo durante un periodo menor al año.

Las cuentas que aquí estarían incluidas son los inventarios que mediante su rotación se esperaría generar ingresos, las cobranzas de acuerdo a las políticas que maneje la empresa y en 
función del tipo de producto que hará que la recuperación del efectivo sea más rápido o más lento y cualquier otra cuenta relacionada con la actividad principal de la empresa,

Los pasivos circulantes constituyen la fuente de financiamiento producto de la operación de la empresa, en muchos casos se consideran cuentas “espontáneamente generadas” ya que su movimiento viene de la mano con la generación misma de las ventas como son: cuentas por pagar relacionadas con pago a proveedores por aumento en la compra de materia prima que aumenta también el volumen del crédito otorgado, sueldos y salarios por pagar, cuyo incremente obedezca a la contratación de nuevo personal operativo y pago de horas extras al personal existente como resultado de una mayor producción encaminada a mayores ventas, entre otras cuentas. (NOF).

La figura 2 refleja gráficamente el concepto de Necesidades Operativas de Fondos

La construcción del flujo de caja libre (FCF) parte de la elaboración de un Estado de Resultados, el mismo que refleja la pérdida o ganancia de la empresa al término de un periodo contable. Sin embargo, este es apenas un insumo para la preparación del FCF pues el concepto detrás de su elaboración aborda la idea de determinar el dinero generado por el negocio de la empresa.

En la tabla 4 se presenta un esquema muy básico de Estado de Resultados y de Utilidades Retenidas, información contable necesaria para conocer al final del periodo lo generado por el negocio y lo disponible para reinvertir en la empresa visualizándose hacia inversiones futuras.

Sin embargo, para la realización de un flujo de caja libre como materia prima de valoración corporativa, se requiere partir de la Utilidad antes de intereses e impuestos (EBIT) para avanzar sin considerar el efecto del endeudamiento, pues en primera instancia se desea conocer los flujos que genera la empresa independientemente de cómo esté financiada, ya que al incluir deuda dentro de su estructura de capital aparecen beneficios tales como los escudos fiscales (ahorro en el pago de impuestos por el uso de la deuda, que genera gastos por intereses disminuyendo la base o utilidad gravable).

Balance contable y balance financiero de una empresa

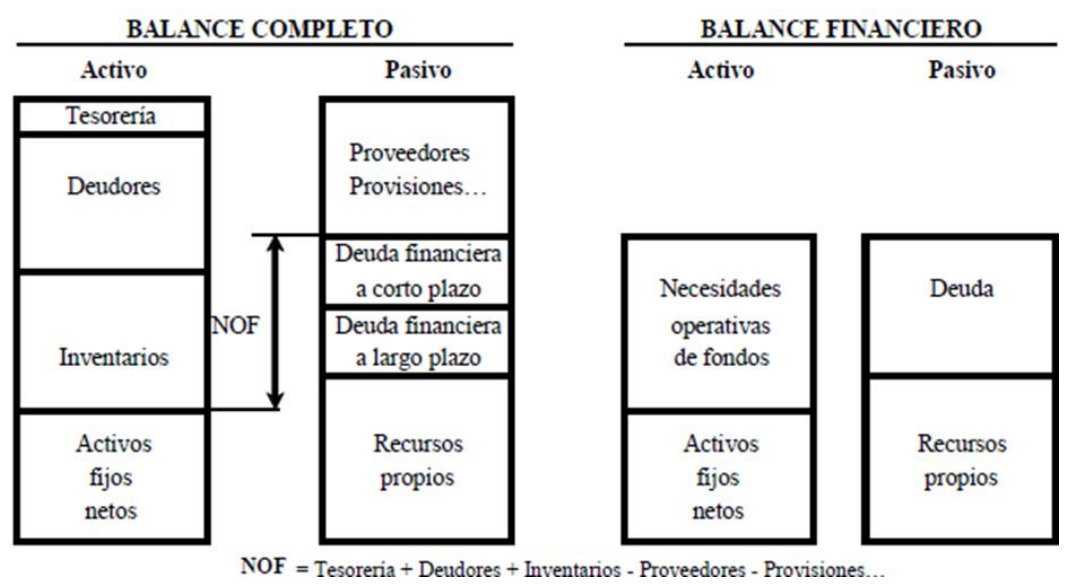

Figura 2 
Tabla 4

\begin{tabular}{l}
\hline Ventas \\
\hline (-) Costo de Ventas \\
(=) Utilidad Bruta en Ventas \\
(-) Gastos de administración \\
(-) Gastos de Ventas \\
(-) Depreciaciones \\
(-) Amortizaciones contables \\
(+) Intereses ganados \\
(=) Utilidad antes de intereses e impuestos (EBIT) \\
(-) Gastos por intereses \\
(=) Utilidad antes de impuestos (EBT) \\
(-) Impuesto a la renta \\
(=) Utilidad / Beneficio Neto \\
(-) Dividendos \\
(=) Utilidad / Beneficios retenidos
\end{tabular}

En la tabla 4A se puede apreciar la transformación de parte del Estado de Resultados y de Utilidades Retenidas en un Flujo de Caja Libre.

Para el flujo de caja libre se parte del EBIT y del cálculo de impuestos sobre este rubro, considerando cuánto la empresa debería haber pagado por la Utilidad generada por las ventas independientemente de cómo se consiguió el dinero para financiar las operaciones de la empresa.

Otra interpretación sería, evaluar si los dueños de la empresa hubiesen puesto el cien por ciento de las necesidades de financiamiento, cuál sería el flujo de caja resultante de esta decisión.

Luego de calcular el impuesto considerando la empresa sin endeudamiento, se procede a calcular su Utilidad o Beneficio Neto, para proceder a sumarle aquellas cuentas que no representan salidas de dinero en efectivo, como son las depreciaciones y amortizaciones cuyo efecto es netamente contable.

Cuentas relevantes adicionales en el camino a la elaboración del FCL la constituyen las inversiones (compras) de activos fijos necesarios para el normal funcionamiento de la empresa (renovación de equipos, expansión de fábrica, aumento de producción, entre otros motivos) así como la venta de activos fijos (generalmente por término de vida útil, obsolescencia, reemplazo por uno más eficiente, falta de uso, etcétera). El primer criterio constituye salidas de dinero para la empresa y el segundo entradas de dinero para la empresa.

Por último, se considerarán los incrementos o disminuciones de las necesidades operativas de fondos NOF (disminuciones o incrementos de efectivo), que como se mencionó anteriormente están encaminadas a cubrir necesidades de corto plazo de la empresa asociadas con su normal funcionamiento y operatividad de la misma y que por un tema de estrategia deberán ser cubiertos con fondos de corto plazo para no caer en un problema de insolvencia financiera en caso de no contar con los fondos requeridos suficientes para cubrirlos en el futuro. 
Tabla $4^{\text {a }}$

Utilidad antes de intereses e impuestos (EBIT)
(-) Impuesto a la renta
(=) Utilidad / Beneficio neto (sin considerar endeudamiento)
(+) Depreciaciones
(+) Amortizaciones contables
(-) Inversiones adicionales en activos fijos
(+) Ventas de activos fijos
(-) Incrementos NOF
(+) Disminuciones NOF
(=) Flujo de caja libre (FCF)

\begin{tabular}{|l|r|r|r|}
\cline { 2 - 4 } \multicolumn{1}{c|}{} & 2001 & 2002 & 2003 \\
\hline Ventas & 1.000 & 1.100 & 1.200 \\
-Coste de mercancías vendidas & -550 & -610 & -660 \\
-Gastos generales & -200 & -220 & -240 \\
-Amortización & -100 & -110 & -120 \\
Beneficio antes de intereses e impuestos (BAIT) & 150 & 160 & 180 \\
\hline -Pagos de intereses & -50 & -60 & -60 \\
Beneficio antes de impuestos (BAT) & 100 & 100 & 120 \\
-Impuestos (30\%) & -30 & -30 & -36 \\
Beneficio neto (BDT) & 70 & 70 & 84 \\
\hline -Dividendos & -50 & -55 & -60 \\
Beneficios retenidos & 20 & 15 & 24 \\
\hline
\end{tabular}

Figura 3

Flujo de fondos libre (free cash flow) de Rahnema, S.A.

\begin{tabular}{|l|r|r|r|}
\cline { 2 - 4 } \multicolumn{1}{c|}{} & 2001 & 2002 & 2003 \\
\hline Beneficio antes de intereses e impuestos (BAIT) & 150 & 160 & 180 \\
-Impuestos sobre el BAIT (30\%) & -45 & -48 & -54 \\
Beneficio neto de la empresa sin deuda & 105 & 112 & 126 \\
\hline +Amortización & 100 & 110 & 120 \\
-Incremento de activos fijos & -60 & -66 & -72 \\
-Incremento de NOF & -10 & -11 & -12 \\
\hline Free cash flow & 135 & 145 & 162 \\
\hline
\end{tabular}

Figura 4

Se debe recordar que los impuestos se calculan sobre el beneficio antes de intereses e impuestos (BAIT / EBIT por sus siglas en inglés), para obtener el beneficio neto sin tener en cuenta los intereses. También se denomina Beneficios antes de Intereses y después de impuestos (BAIDI).

En la figura 5 se presenta una ilustración que trata de graficar lo explicado anteriormente: 


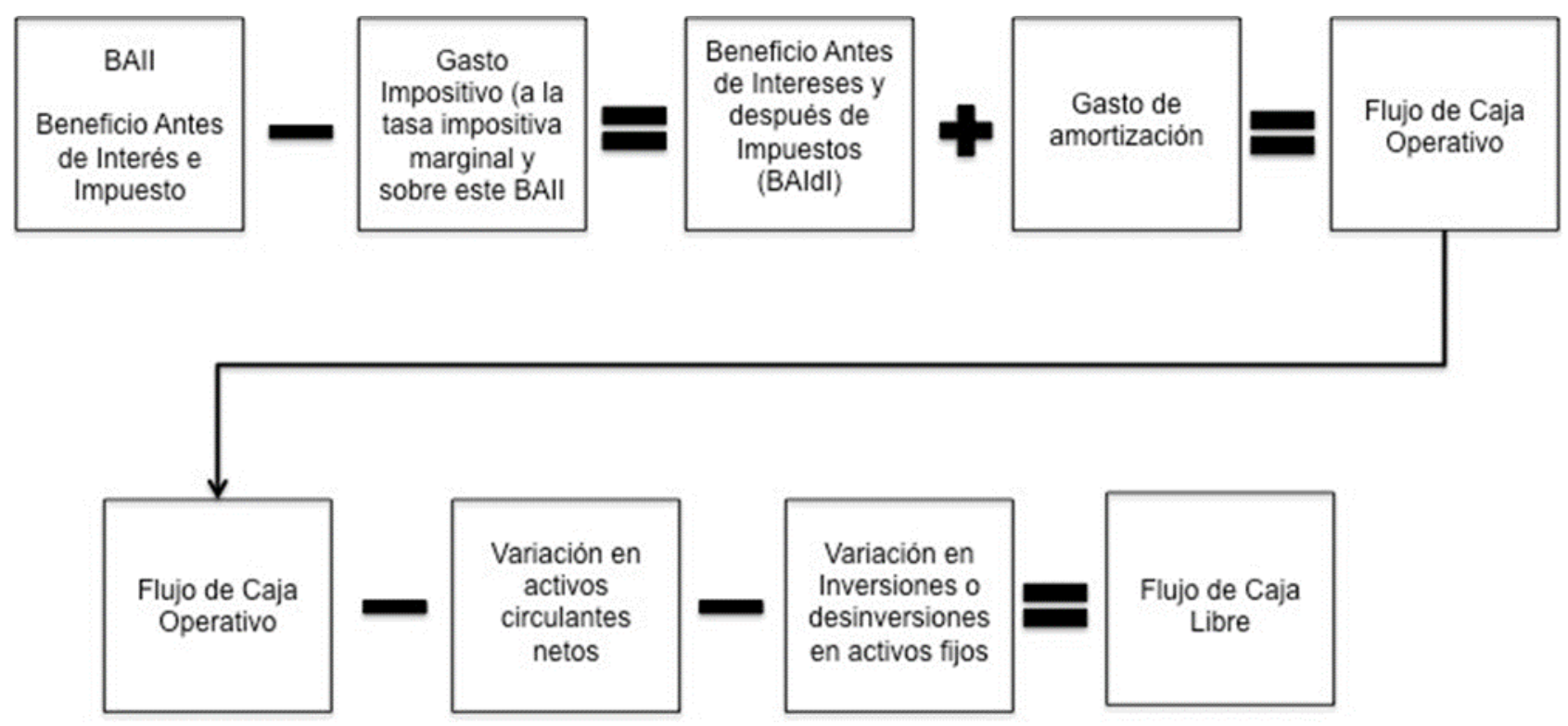

Figura 5

El flujo de caja libre supone prescindir de la financiación de la empresa, para centrarse en el rendimiento económico de los activos después de impuestos, visto de una perspectiva de empresa en marcha y teniendo en cuenta en cada periodo las inversiones necesarias para la continuidad del negocio. Si la empresa no tuviera deuda el flujo de fondos libre sería igual que el flujo de fondos para los accionistas

La figura 6 describe una forma resumida de la fórmula de valoración de empresas por flujo de caja descontados, incluyendo la tasa de descuento adecuada WACC (costo de capital promedio ponderado en español) que representa la mínima tasa de rendimiento que deberá generar la empresa en función de los activos en que ha invertido para poder devolverle a sus inversionistas el costo de oportunidad (tasa de interés ofrecida a accionistas y acreedores) por el uso de sus recursos.

El WACC (o CCPP) es un tasa de interés calculada en función del promedio ponderado que depende de la estructura de capital que maneje la empresa, es decir en función de la forma en la que se encuentra financiada. 


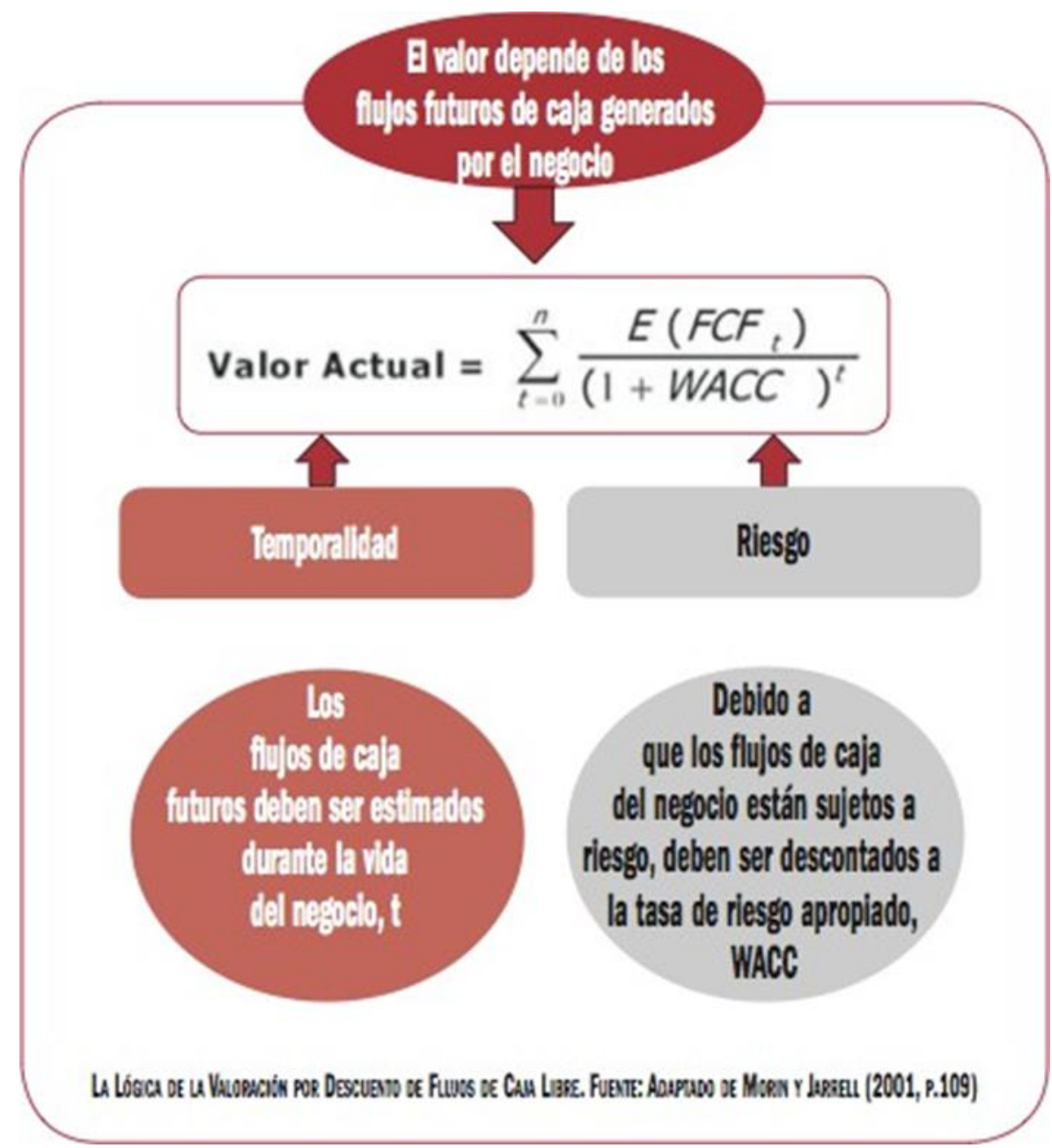

Figura 6

A continuación se presenta otro ejemplo de valoracion (figura 7) por descuento de flujos de caja en esta ocasión de OHMS S.A. Ejemplo dado en millones de Unidades Monetarias (UM):

\begin{tabular}{|c|c|c|c|c|c|c|c|}
\hline & $1998 R$ & 1999E & $2000 E$ & $2001 E$ & 2002E & 2003E & VR \\
\hline 1 BAIDI & 2.603 & 2.534 & 2.361 & 744 & 485 & 214 & \\
\hline 2 +Amortización & 1.704 & 2.187 & 2.327 & 2.430 & 2.533 & 2.605 & \\
\hline 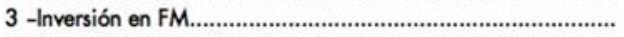 & 203 & -329 & 115 & 116 & 117 & 119 & \\
\hline 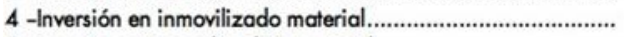 & 148 & & & & & & \\
\hline 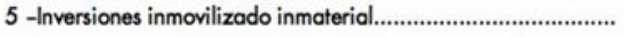 & 900 & 1.010 & 1.020 & 1.030 & 1.041 & 1.051 & \\
\hline 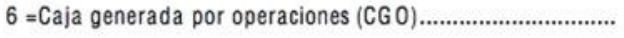 & 3.056 & 4.040 & 3.553 & 2.027 & 1.860 & 1.649 & 21.030 \\
\hline 7 VA de las CGO al 10 por 100 & 10.427 & & & & & & \\
\hline 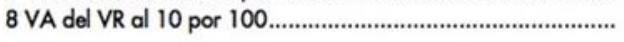 & 13.058 & & & & & & \\
\hline 9 Valor de los activos & 23.485 & & & & & & \\
\hline $10+$ Caja & 10.923 & & & & & & \\
\hline 11 -Deuda & 5.931 & & & & & & \\
\hline 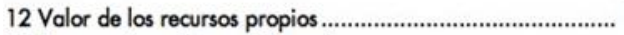 & 28.477 & & & & & & \\
\hline 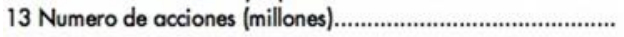 & 13,62 & & & & & & \\
\hline 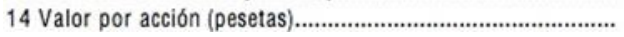 & 2.091 & & & & & & \\
\hline
\end{tabular}

Figura 7 
Este ejemplo corresponde a una empresa española. Los BAIDI reales al 2008 eran 2.603 millones de UM. Las cuentas de resultados para los años 1999-2003 son estimados y están colocadas en la fila 1 de la tabla.

En la fila 2 están las amortizaciones, en las filas 3,4 y 6 se encuentras las inversiones estimadas a realizar. Las inversiones no son pagos que se incluyen en los gastos de la cuenta de resultados. La fila 6 es la caja generada por las operaciones (CGO) o el flujo libre de caja generado $(\mathrm{FCF})$

El valor residual VR se lo obtiene así para este caso:

$$
V R=\frac{\Gamma \iota ! " " \#}{R-g}=\frac{1.04 y \times 1, \mathrm{v} \iota}{0,10-0,02}=21.030
$$

Considerado una tasa de crecimiento del $2 \%$ (g) y costo de oportunidad para los inversionistas del $10 \%(\mathrm{R})$.

En la fila 7 está el valor actual de los flujos de caja y en la 8 el valor actual del valor residual, ambos calculados a una tasa del $10 \%$. Si a éstos se le suma la caja y se le resta la deuda, se obtiene el valor de los recursos propios que, dividido por el número de acciones, proporciona el valor teórico de la acción, 2.091 UM.

Para calcular el valor de la empresa por este método, se realiza el descuento de los flujos, utilizando el WACC que se plantea en la ecuación 8:

$$
W A C C=\frac{E R e+D R d(1-T)}{E+D}
$$

Donde

E: Valor de mercado de patrimonio de la empresa.

D: Valor de mercado de la deuda de la empresa.

Re: Rentabilidad exigida por los accionistas.

Rd: Rentabilidad exigida por los acreedores (dueños de la deuda)

T: Impuesto a las utilidades que efectivamente paga la empresa, luego de aplicar la conciliación tributaria.

\section{Flujo de Caja del capital}

El Flujo de Caja del Capital refleja en los flujos de caja el escudo fiscal generado por los gastos financieros. Corrige el efecto del flujo de caja libre. Es el flujo de disponible para retribuir a los recursos permanentes que financian el proyecto, es decir la deuda y los recursos propios. Es el flujo que queda para pagar dividendos, devolver la deuda y pagar intereses.

A diferencia del FCL, el efecto fiscal por la existencia de gastos financieros se incluye en los flujos y no en la tasa de descuento.

Se tiene que:

$F C C=F C F+$ Gastos Financieros $x t(9)$ 
Otra forma de describir el Flujo de Caja del Capital, es como la suma del flujo de caja para acreedores (poseedores de deuda) más el flujo de caja de los accionistas. El flujo de caja de los acreedores se compone de la suma de los intereses más la devolución del principal.

La ecuación 10 describe la representación del Flujo de caja del capital:

$$
F C C=F C a c+F C d=F C a c+I-\Delta D(10)
$$

Siendo I intereses (gastos financieros producto de la deuda), otra forma de calcularlo es producto de la multiplicación de la deuda (D) por la tasa de la deuda Rd.

\section{Flujo de caja del accionista}

El flujo de caja libre para los accionistas (FCac o CFAcc) es el efectivo disponible después de las inversiones requeridas y el pago del servicio de la deuda para retribuir a los propietarios.

Esquemáticamente se parte de la figura 8 donde se refleja un Flujo de caja libre básico:

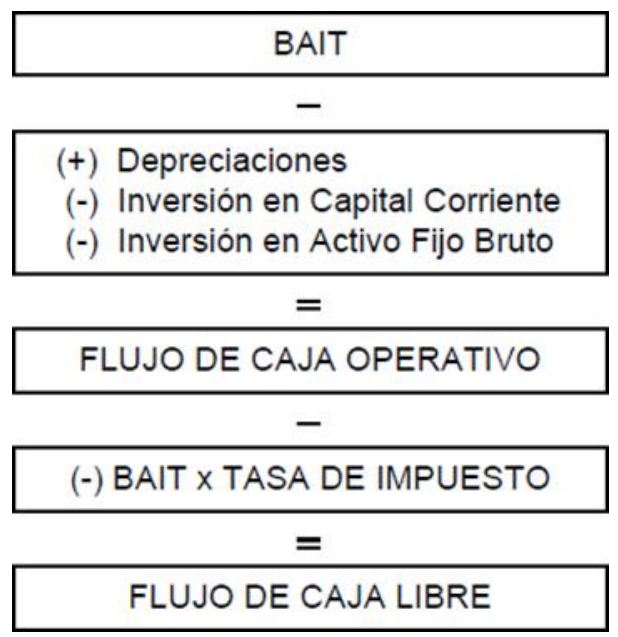

Figura 8

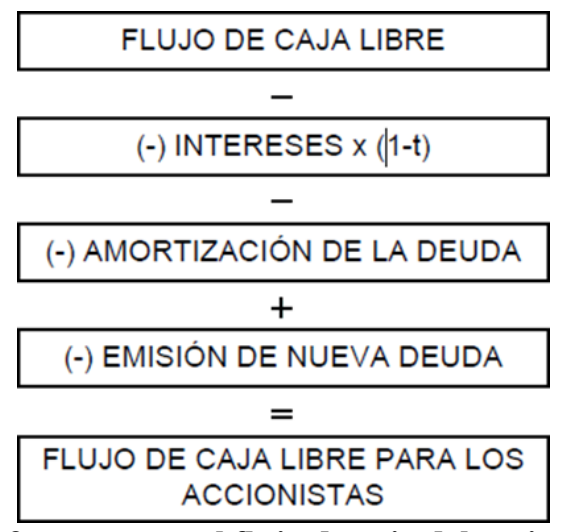

Figura 9: La figura 9 representa el flujo de caja del accionista esquematizado 
Para estimar este flujo es conveniente conocer la estructura financiera de la empresa por periodo, puesto que esta estructura dependerá del tamaño de la deuda y su costo.

Lo que quede tras satisfacer las necesidades de deuda, será usado para remunerar a los tenedores de las acciones de la empresa de acuerdo con la política de dividendos, por medio de la recompra de acciones o pago de dividendos, o para la reinversión en la empresa.

Se puede estimar el valor de la empresa para el propietario descontando los flujos de caja libres para el accionista a la tasa Ke. Una equivocación muy común al descontar el FCac es la inconsistencia entre la tasa de descuento y la política de dividendos. Por ejemplo, si una empresa incrementa dividendos pero la utilidad se mantiene igual se deberá ajustar la tasa de descuento del FCac por el aumento en el riesgo. Si no se realiza el ajuste la valoración será equivocada.

Si se crea valor para el accionista es claro que cuantos más altos sean los FCac y más bajo el riesgo que está implícito en la tasa de descuento, la creación de valor será mayor.

Se debe tener presente que este flujo es dependiente de la estructura financiera de la empresa y, en consecuencia, de su política de dividendos por lo que el posible uso de recursos propios o ajenos estará en función del payout (pago de dividendos) o de la tasa de reinversión del beneficio.

\section{Flujo de caja de la deuda}

Son fondos netos disponibles para los acreedores. El cálculo del flujo de caja de la deuda es, en principio, el más simple dado que incorpora solo los gastos financieros y las variaciones del principal de la deuda.

En los Gastos Financieros se incorporan intereses y comisiones pagadas por deudas asumidas con instituciones financieras.

Modelo de Gordon y Shapiro El modelo de Gordon - Shapiro es un modelo de descuento de dividendos de una etapa, usado para determinar el valor intrínseco de una acción sobre la base de una serie futura de dividendos que crecen a una tasa constante.

Dado un dividendo por acción que es pagable en un año y el supuesto que el dividendo crece a una tasa constante a perpetuidad, el modelo resuelve el valor presente de una serie infinita de dividendos futuros.

El modelo de descuento de dividendos puede ser de una etapa, como el caso del modelo de Gordon - Shapiro o multietapas, es decir, un modelo de dos o tres etapas.

El modelo de descuento de dividendos (MDD) es la herramienta financiera empleada para valorar las acciones de una empresa de acuerdo con el valor presente de los dividendos futuros que esta pagará.

Estos dividendos futuros dependerán de la naturaleza de los mismos y para ello, diferentes autores han planteado tres fórmulas que buscan modelar la condición que presentan 
los dividendos de las acciones en el trascurso del tiempo. Una de estas fórmulas es la de Gordon y Shapiro. Como ya se mencionó en la parte introductoria, el modelo de descuento de dividendos puede ser de una etapa pero también hay modelos multietapas, que se caracterizan porque aplican distintas tasas de crecimiento de dividendos, en diferentes periodos de tiempo.

El modelo de una etapa permite calcular el precio de la acción de una empresa hoy, con una sola etapa de crecimiento estable. El modelo de dos etapas está diseñado para calcular el precio de la acción de una empresa hoy, con dos etapas de crecimiento, un periodo inicial de crecimiento mayor y uno subsecuente de crecimiento estable.

Supone que la empresa espera crecer a una tasa alta durante un primer periodo, pero esta tasa cae al final del primer periodo a una tasa estable. El ratio de pago de dividendos (Payout Ratio) es consistente con la tasa de crecimiento esperada. Además, asume que este ratio y el costo de las acciones (Equity) son constantes, lo que determina limitaciones al modelo.

Se puede aplicar el modelo de descuento de dos etapas para calcular el valor de una acción cuando los dividendos tienen dos tasas de crecimiento. Para esto se supone que el Dividendo por Acción (DPA) y el Beneficio por Acción crecen a la tasa g hasta el año n y que a partir del año $n+1$ crecen a la tasa g, que es sencillamente la tasa de crecimiento de dividendos que se caracteriza por ser menor respecto a la del primer periodo. Luego, el dividendo por acción del año n es:

$$
D P A !=D P A !(1+g) ! ! !(11)
$$

Donde:

DPAn: Dividendos por acción en el período " $n$ "

g: Tasa de crecimiento de los dividendos por acción

n: Número de períodos

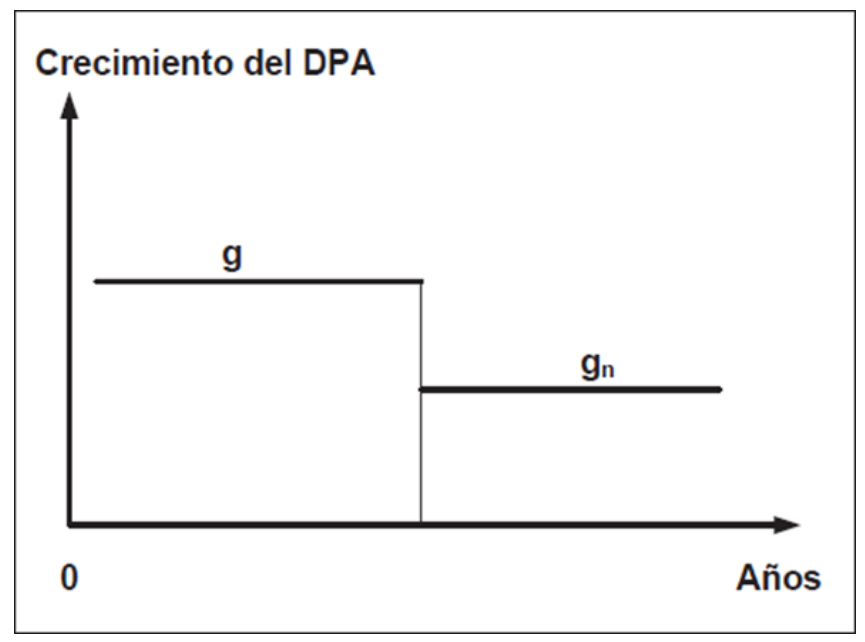

Figura 10

La figura 10 describe varios comportamientos de crecimientos de los dividendos a través del horizonte de valoración. 
La fórmula de Gordon y Shapiro plantea que el dividendo por acción crece a una tasa o porcentaje fijo "g" en cada período. Así también muestra que el valor de una acción hoy es igual al dividendo por acción descontado por la diferencia entre la rentabilidad mínima exigida por los accionistas [modelo CAPM (Ke)] y la tasa de crecimiento.

Se plantean tres hipótesis:

a) Dividendos pagados en porcentajes a lo largo del tiempo.

b) Tasa de rendimiento constante para todas las inversiones futuras de la empresa.

c) Descuento de los dividendos esperados a una tasa constante de rentabilidad exigida.

Donde:

DPAt Dividendo por acción en el período “ $\mathrm{t}$ ” $(\mathrm{t}=0,1,2,3)$

Ke Costo del capital propio (Equity)

gi Tasa de crecimiento de los dividendos en el período " $t$ "

Para que los beneficios adicionales que obtenga la sociedad sean tenidos en cuenta por el mercado, la rentabilidad esperada de las nuevas inversiones debe ser superior al rendimiento exigido por los accionistas.

\section{Comparación de los modos de valoración}

Topa (2012) ha resumido los aspectos más relevantes de los métodos de valoración que se presentaron anteriormente. Ella muestra el mayor o menor grado de uso, o de incidencia, de ciertos aspectos involucrados en los métodos de valoración la cual se aprecia en la figura 11. Su estudio lo ha realizado considerando la realidad colombiana. Una línea de investigación sería realizar el mismo análisis comparativo para el Ecuador.

\begin{tabular}{||l|c|c|c|c|c|c|c|c||}
\hline \multicolumn{1}{|c|}{ Valoración } & $\begin{array}{l}\text { en } \\
\text { libros }\end{array}$ & $\begin{array}{l}\text { ajuste } \\
\text { activos } \\
\text { netos }\end{array}$ & $\begin{array}{l}\text { reposi- } \\
\text { ción }\end{array}$ & $\begin{array}{l}\text { liquida- } \\
\text { ción }\end{array}$ & $\begin{array}{l}\text { en } \\
\text { Bolsa }\end{array}$ & $\begin{array}{l}\text { Múltiplo } \\
\text { de Utili- } \\
\text { dades }\end{array}$ & $\begin{array}{l}\text { caja } \\
\text { descon- } \\
\text { tado }\end{array}$ \\
\hline Uso de Información Objetiva & Alto & Alto & No & No & Alto & Medio & Alto \\
Medición del Rendimiento Económico en Forma Apropiada & No & No & No & No & Medio & Medio & Alto \\
Flexibilidad para Determinar Rango de Valores & No & Bajo & Bajo & Bajo & Bajo & Medio & Alto \\
Facilidad para manipular Rango de Valores & No & Bajo & Bajo & Bajo & Bajo & Medio & Alto \\
Adaptabilidad a Cada Empresa & Alto & Alto & No & No & Medio & Medio & Alto \\
Aporte Constructivo al Proceso de Negociación & No & No & No & No & Medio & Medio & Alto \\
Complejidad Conceptual & No & No & Medio & Medio & No & Medio & Alto \\
Grado de Aceptación & Alto & Alto & Medio & Medio & Alto & Bajo & Bajo \\
Grado de Rapidez para Obtener un Valor & Medio & Medio & Medio & Medio & Alto & Alto & Bajo \\
Grado de Experiencia de los Evaluadores & Medio & Medio & Medio & Medio & Bajo & Bajo & Alto \\
Utilización equipos de computo y sistemas de información & Medio & Medio & Medio & Medio & Medio & Bajo & Alto \\
Costos que conlleva hacer la valoración & Bajo & Bajo & Medio & Medio & Bajo & Bajo & Alto \\
\hline
\end{tabular}

Figura 11 


\section{Valor Económico Agregado (VEA)}

Gallegos Muñoz y Medina Giacomozzi (2011) mencionan en su documento

"Determinación del valor económico añadido: un modelo alternativo" que la creación de valor económico es el norte que mueve a toda empresa, por lo tanto, es crucial establecer su valor económico, para lo cual existe una diversidad de procedimientos. Entre todos ellos, destaca el método del valor económico añadido (VEA), el cual tiene la virtud de comparar el rendimiento de la inversión con su costo de financiamiento.

La propuesta metodológica es de mucha utilidad, pero en su delimitación no permite distinguir el VEA proveniente de los efectos del negocio con los VEA generados por otros resultados, por lo que ese artículo plantea una nueva forma de determinar el VEA que permite diferenciar y distinguir los VEA creados por los diversos resultados que podría obtener la empresa.

En este contexto, la base sobre la cual se sustenta la creación de valor económico en la empresa descansa en la capacidad de la entidad de obtener un rendimiento de la inversión por sobre el costo de financiamiento de dicha inversión, por lo que, como norma general, la dirección de la empresa debe estar muy atenta a la maximización del valor más que al rendimiento de por sí.

El costo de financiamiento es la línea divisoria e invisible que separa la buena o mala gestión de la alta administración; es decir, si esta no ha logrado generar rendimiento sobre la inversión (RSI) por sobre el costo de financiamiento, no se estará creando valor. Por tal motivo, siempre se debe contrastar el beneficio operacional neto menos impuestos ajustados, con la cantidad de UM que se generan al aplicar sobre la inversión inicial la tasa de costo de financiamiento de dicha inversión.

Es preciso señalar que aquí lo importante no es aumentar la cifra porcentual de rendimiento de la inversión media del total de inversiones que se mantengan, sino evaluar la capacidad para maximizar en el largo plazo, es decir la cantidad de valor que agrega en UM generadas de la diferencia producida entre el beneficio operativo ajustado por impuestos, menos la inversión inicial multiplicada por su respectivo costo de financiamiento. Solo de este modo y si el resultado es positivo, se puede afirmar que la empresa ha creado valor.

En la determinación del valor económico de la empresa también se parte de que la empresa tiene una vida indefinida y continua, lo que produce dos escenarios: el coyuntural y el estructural.

a) Escenario coyuntural: corresponde al periodo de tiempo, ya sea pasado o futuro, sobre el cual la empresa es capaz de recabar información útil que le permita generar los flujos de cada periodo. Por lo tanto, mientras más largo sea este escenario coyuntural producto de la información que se posea, mayor podrá ser el grado de acierto en la valoración, por lo que este periodo corresponde a la parte finita de la proyección. 
b) Escenario estructural: concierne al periodo de tiempo sobre el cual no existe información o los datos son muy inciertos. Por lo tanto, este tiempo posterior al último año proyectado del periodo coyuntural, que es indefinido, también debe ser considerado dentro del proceso de valoración de la empresa mediante la determinación del valor de continuidad como valor terminal para una perpetuidad.

La determinación del valor económico por medio del VEA (Economic Value Added, EVA) fue creado por la consultora Stern Stewart \&Co ${ }^{5}$. para la valoración de empresas.

\section{La estrategia y la creación de valor}

Crear valor es la meta de los gerentes actuales. Si antes el objetivo era maximizar utilidades, ahora es crear valor. Es posible hacer una medición del valor que ha sido creado teniendo en cuenta no solamente el beneficio, sino además el costo incurrido en producir este último.

La finalidad es asignar recursos a actividades que no producen los mayores beneficios inmediatos. La capacidad de una empresa para crear valor para la sociedad es producto de una filosofía del management.

Empresa no solo como entidad económica, sino como institución social que permite a los individuos variar su comportamiento a como lo harían en un mercado. La creación de valor es el objetivo de toda buena gerencia (la maximización del valor de la inversión realizada por los accionistas).

Grant (1991) afirma que el objetivo de la Planificación Estratégica, es permitir que la empresa obtenga una ventaja sostenible sobre sus competidores. Barney (1991) afirma que Op. Cit. entender las fuentes de las Ventajas Competitiva de las firmas has sido uno de los mayores temas de investigación en el campo del management estratégico.

Jiménez y Andalaft (2002) afirman que distintas corrientes de pensamiento han tratado de responder que permite obtener una rentabilidad superior a la de los competidores y que sea sostenible en el tiempo, con el propósito de explicar de qué depende la ventaja Competitiva y como alcanzarla. Según Bowman (1974) la estrategia ha sido enfocada como una búsqueda continua de renta.

Según Porter (1987) una empresa alcanza la ventaja competitiva cuando obtiene rendimientos superiores; es decir, cuando la rentabilidad de una empresa excede el costo de oportunidad de los recursos empleados para la provisión de su bien o servicio. La teoría de Michael Porter considera que las empresas se encuentran en mitad de un conjunto de fuerzas de competencia que arrojan a cada una de ellas contra todas las demás. La dificultad reside en que los intereses de la empresa son incompatibles con los de la sociedad, ya que ésta se beneficia de la competencia que haya entre las empresas.

Rappaport (2006) señala que hay diez maneras de crear valor para los accionistas

${ }^{5}$ Op. Cit. 
1. No manejar ganancias ni entregar una guía de ganancias

2. Tomar decisiones estratégicas que maximicen el valor esperado, incluso a expensas de menores ganancias a corto plazo.

3. Hacer adquisiciones que maximicen el valor esperado, incluso a expensas de menores ganancias a corto plazo.

4. Mantener solamente activos que maximicen el valor.

5. Devolver el efectivo a los accionistas cuando no existan oportunidades creíbles de creación de valor para invertir en el negocio

6. Recompensar al CEO y a otros altos ejecutivos por generar retornos superiores en el largo plazo.

7. Recompensar al CEO y a otros altos ejecutivos por generar retornos superiores en el largo plazo.

8. Recompensar a los ejecutivos medios y a los empleados en la primera línea por entregar un desempeño superior en los impulsores clave del valor en que ellos influyen directamente.

9. Exigir que los altos ejecutivos asuman los riesgos de la propiedad al igual que los accionistas.

10. Entregar a los inversionistas información relevante sobre el valor 


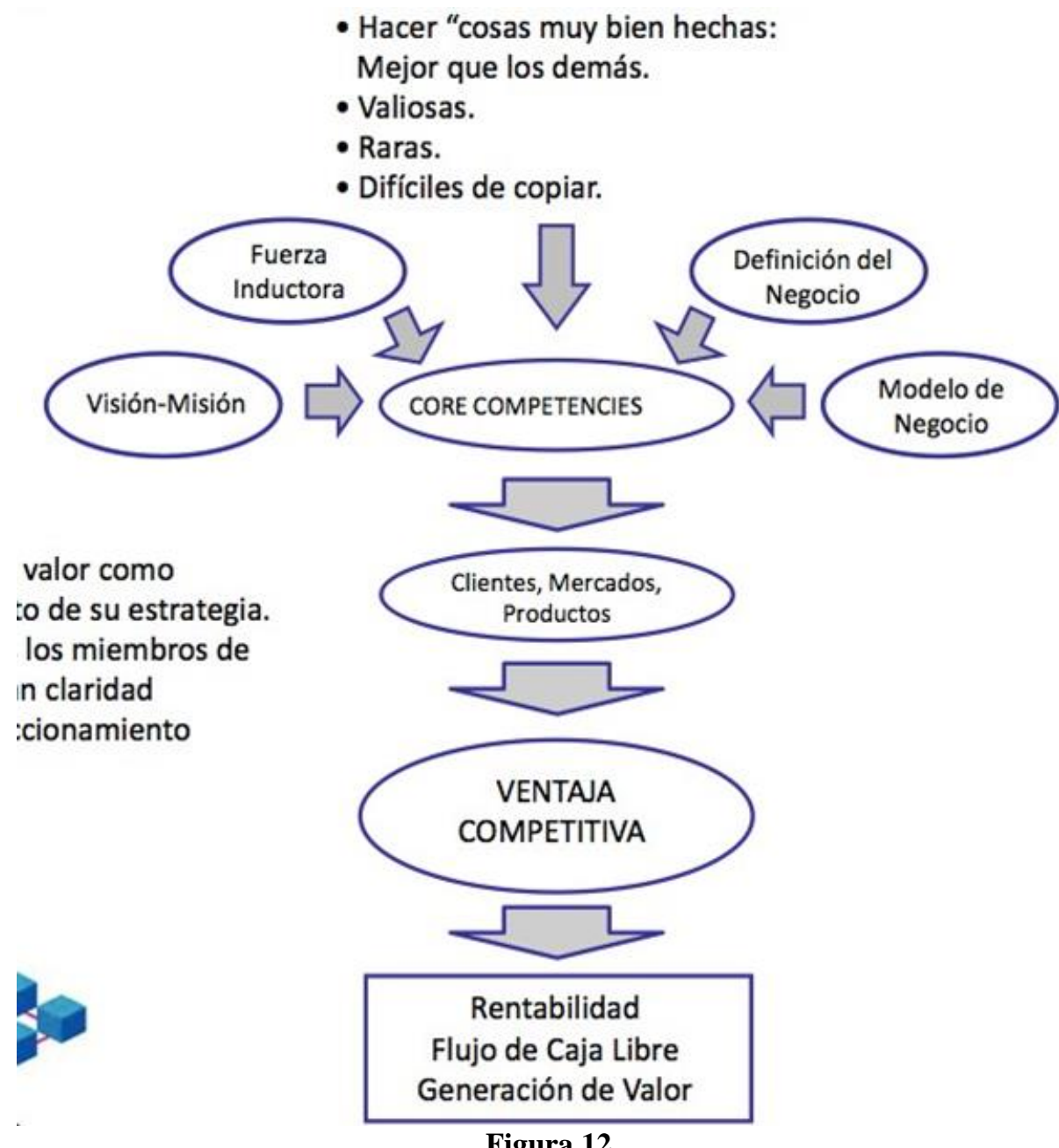

Figura 12

El VAN es la herramienta que mejor mide la creación de valor. Para realizar estimaciones del rendimiento futuro de una empresa hay que estudiar el rendimiento pasado, basándonos en el análisis del flujo de caja libre y en el de los elementos creadores de valor de la empresa: La tasa de rendimiento sobre la inversión (ROI) y la tasa de inversión neta.

A continuación se presenta una ilustración que resume los factores creadores de valor para una empresa, considerando el valor agregado que se desea obtener de la misma para maximizar su valor en el mercado.

En la Figura 13, si de izquierda a derecha y de arriba hacia abajo se analiza el esquema, se observa que el primer elemento es g, que representa crecimiento. El crecimiento depende del

ROE y de b, la tasa de retención de beneficios, que a su vez depende de los objetivos estratégicos de presencia en el mercado y de la política de dividendos de la empresa.

Más a la derecha, la rentabilidad de los recursos propios se enuncia en función de la rentabilidad económica, ROA, del nivel de apalancamiento, D/P, y del costo de los recursos externos, después de impuestos. Con respecto a $\mathrm{Ke}(\mathrm{Re})$, la rentabilidad exigida por los accionistas se ha enunciado dependiendo de su nivel de volatilidad, $\beta$, según el modelo CAPM. 
De acuerdo con el modelo, la prima de riesgo de un activo es directamente proporcional a su riesgo sistemático. Si se relacionan todos los elementos del esquema, se aprecia que las políticas de inversiones, endeudamiento y dividendos influyen en el valor.

También en el cuadro se aprecia como ROA, indicador de cuan rentable es la empresa en relación al total de sus activos netos, se puede expresar como el beneficio sobre ventas por la rotación de ventas sobre activos, lo que conduce a temas de Finanzas Operativas, referidas a cuestiones de eficiencia en la cuenta de resultados (precios, costos, márgenes) como a la gestión financiera de los activos, que incluye todas las acciones de gestión del Fondo de Maniobra.

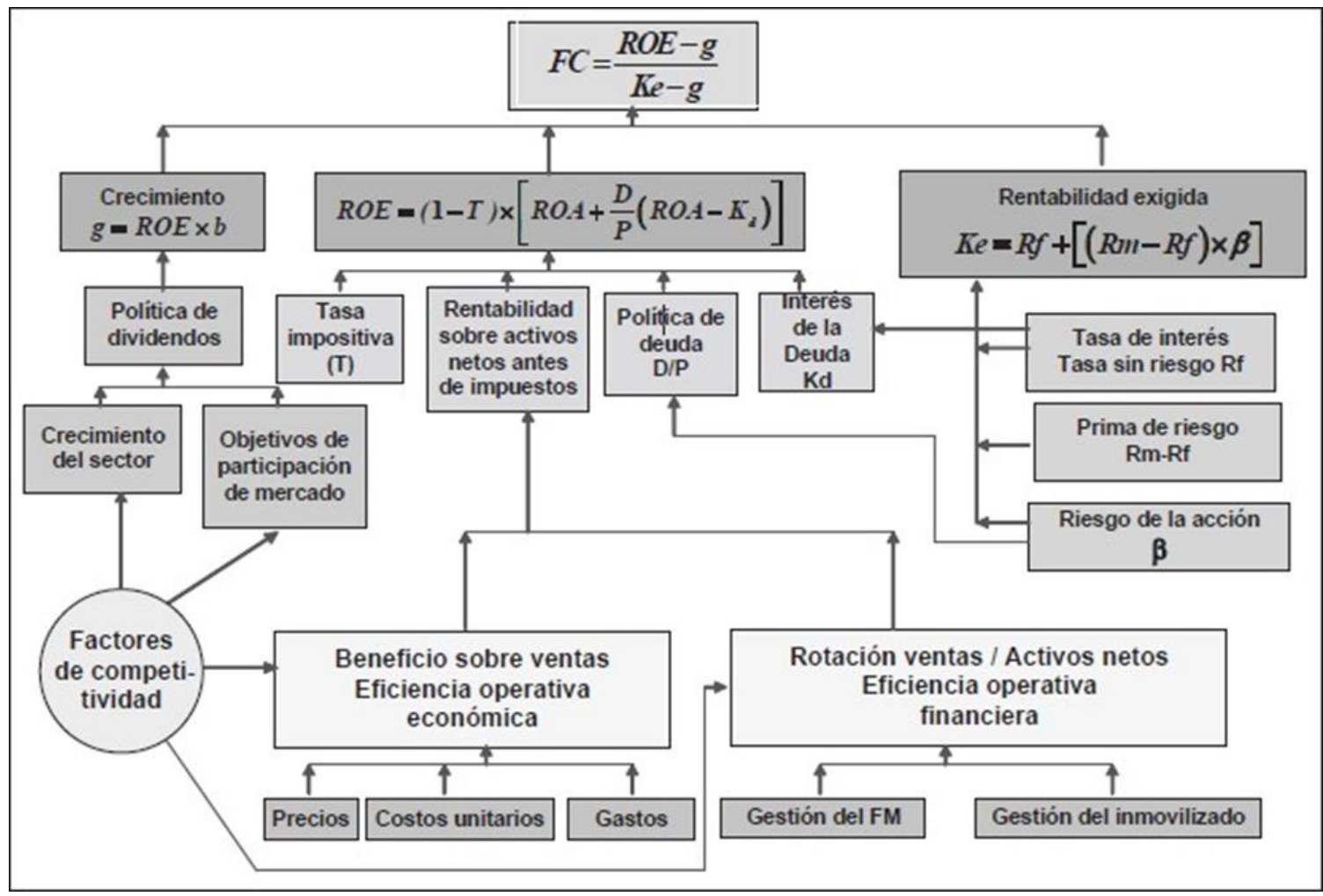

Figura 13

Si ahora se muestra la creación de valor para los accionistas en un año desde el punto de vista externo a la empresa (Bolsa de Valores), se puede definir el aumento de valor para los accionistas como la riqueza que tienen al final de un año menos la que tenían el año anterior.

Para calcular ese aumento de riqueza se tendrá que considerar que incrementos de la capitalización no son necesariamente incrementos del valor para los accionistas. Hay dos posiciones:

1. Aumenta la capitalización pero no el valor para los accionistas cuando: Los tenedores de acciones suscriben nuevas acciones de la compañía desembolsando efectivo, y cuando se convierten obligaciones convertibles (Bonos por acciones). 
2. Disminuye la capitalización, pero no el valor para los accionistas cuando: La compañía paga a los tenedores de acciones (dividendos, reducciones de nominal), y cuando la compañía adquiere acciones en el mercado.

El incremento del valor para los tenedores de acciones se estima así como lo demuestra la tabla a continuación:

Tabla 5

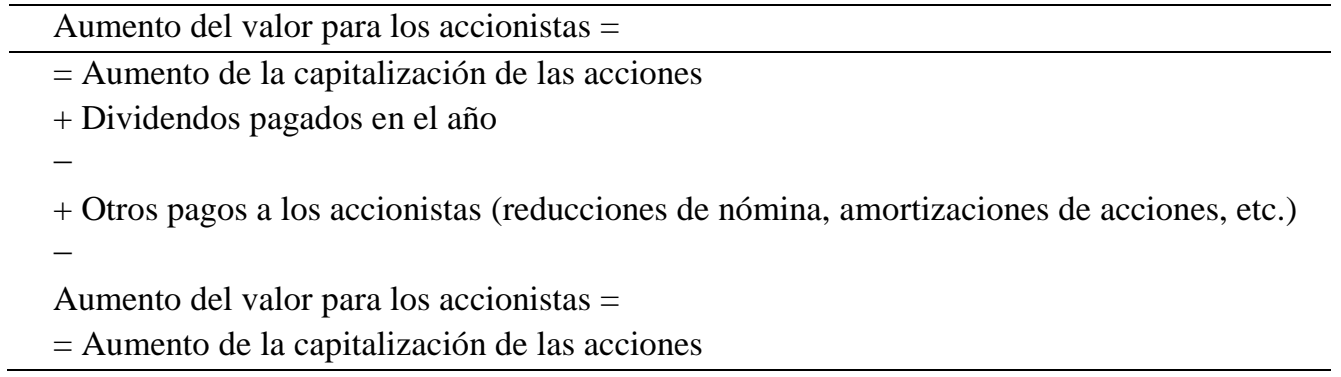

No obstante, el incremento de valor para los tenedores de acciones no es creación de valor para éstos. Para que se cree valor se necesita que la rentabilidad exigida a las acciones sea menor a la rentabilidad para los accionistas.

Esta última rentabilidad para los accionistas se calcula dividiendo el incremento, en un año, del valor para los accionistas entre la capitalización al inicio del año. No obstante, el incremento de valor para los tenedores de acciones no es creación de valor para estos. Para quese cree valor se necesita que la rentabilidad exigida a las acciones sea menor a la rentabilidad para los accionistas.

Por último, una compañía crea valor para los accionistas cuando la rentabilidad para estos supera al costo de las acciones. Es decir, una compañía crea valor cuando se desempeña mejor que las expectativas.

\section{Los Value Drivers O Inductores De Valor Corporativos}

Se crea valor cuando se aumenta en el valor de las acciones de la empresa. Se crea valor cuando se llevan adelante proyectos que poseen con una rentabilidad esperada mayor al costo de los recursos. Court muestra la siguiente figura citando que fue elaborada sobre la base de la tesis "Medición del Riesgo para Empresas Agroindustriales que no Cotizan en Bolsa", hecha por alumnos del Programa de Maestría en Administración de Negocios MSM VII de CENTRUM Católica en el año 2009. 


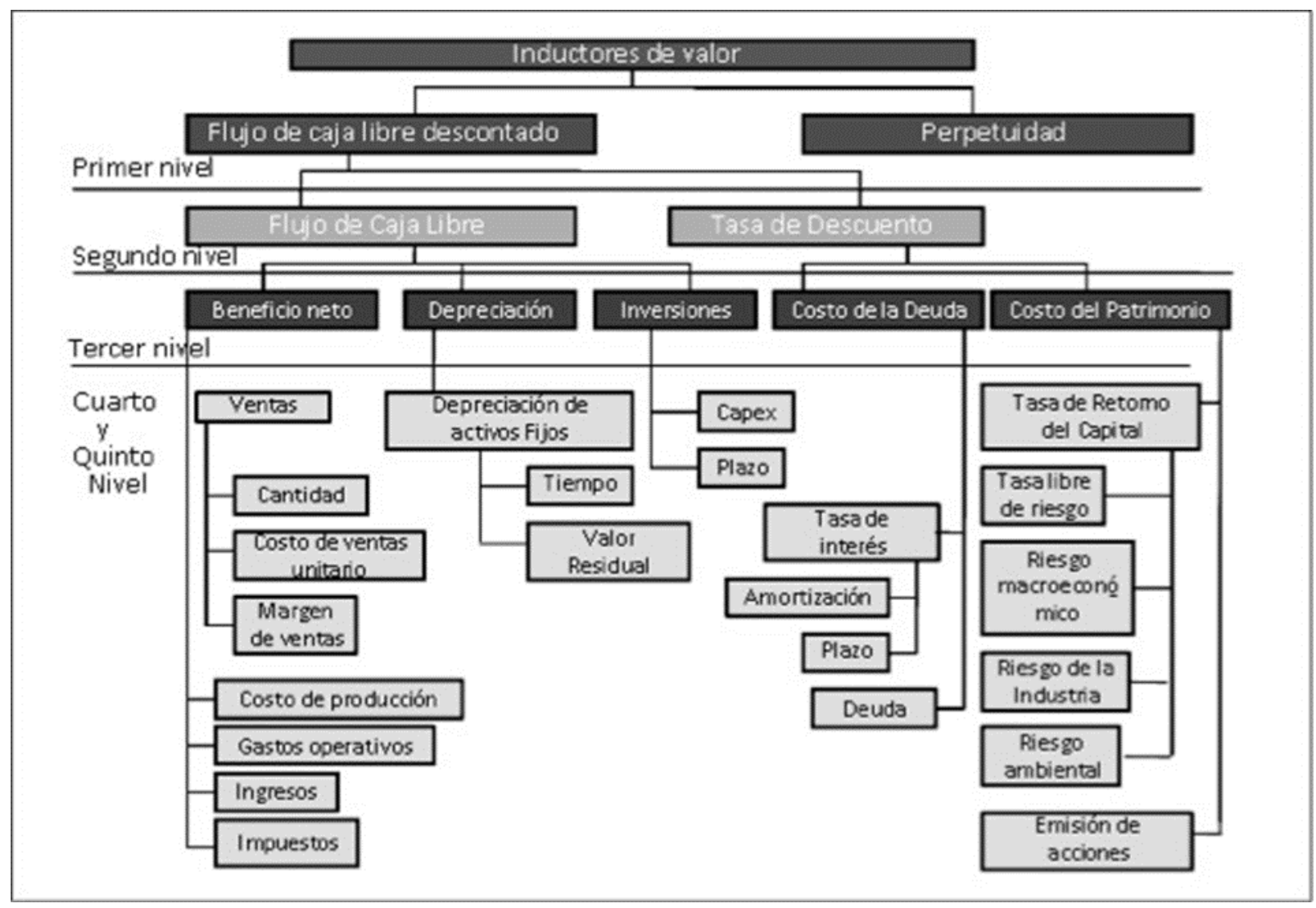

Figura 14

Según este modelo los inductores son de:

a) Primer nivel.- son los flujos de caja libre descontados

b) Segundo nivel.-son los flujos de caja libre y tasa de descuento.

c) Tercer nivel.- Consideran las fuentes de financiamiento del capital de la empresa, es decir deuda y patrimonio, esto permite considerar a los costos de la deuda y de patrimonio como inductores del tercer nivel (del tipo de descuento).

d) Los inductores de cuarto nivel se dividen en dos fuentes, la fuente del beneficio neto que incluyen las ventas, el costo de mercancías vendidas y de los trabajos realizados, gastos operativos, ingresos y el impuesto sobre las utilidades

\section{Los elementos creadores de valor}

Se presenta la figura 15 que resume brevemente los criterios mencionados anteriormente. 


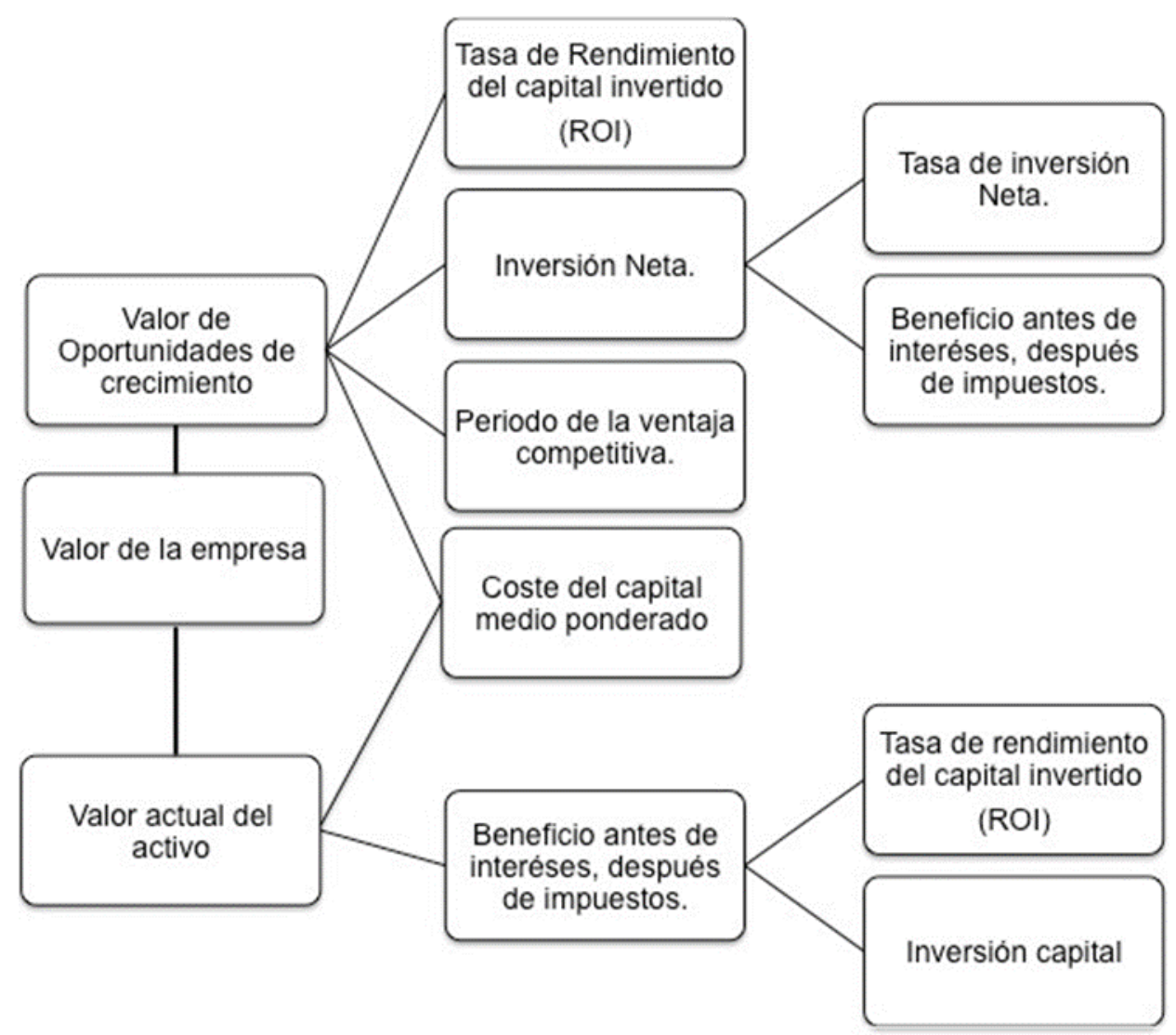

Figura 15: Elementos Generadores de Valor

\section{Relaciones entre el fcf y los inductores de valor corporativos}

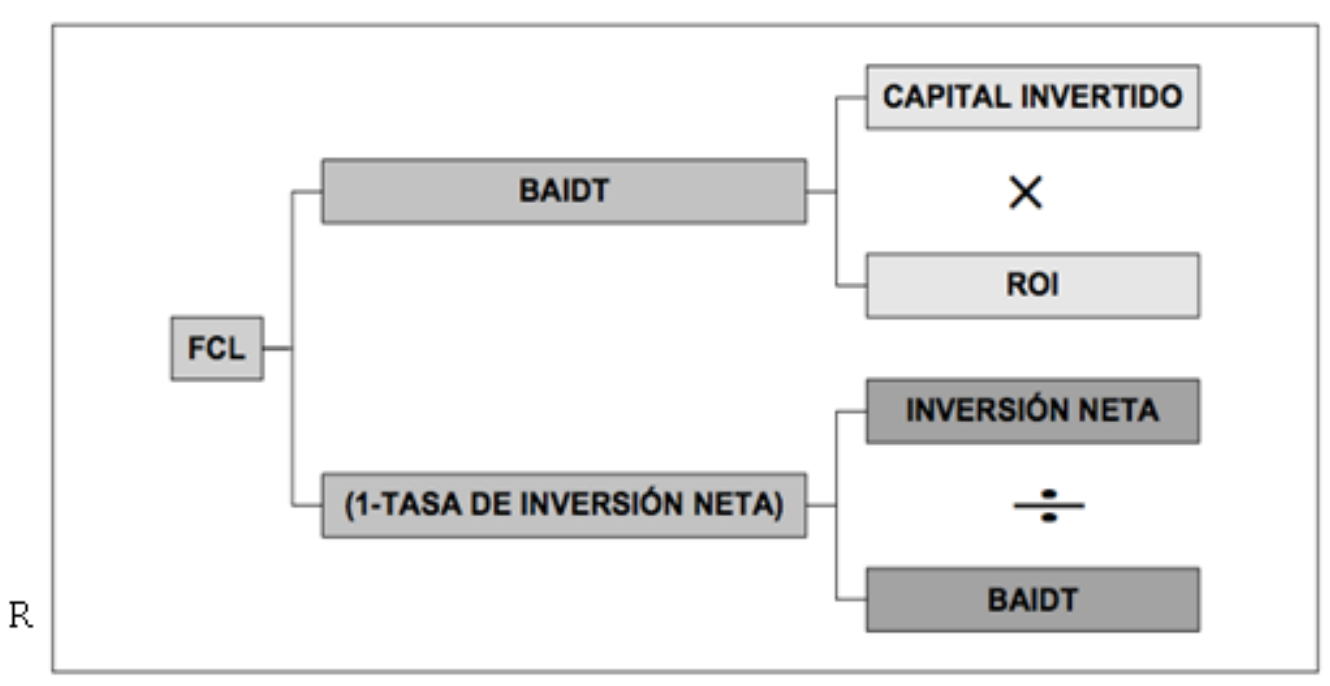

Figura 16: Tasas de descuento relevantes para valoración corporativa.

Es función de la gerencia tomar decisiones que lleven a la maximización del valor de la empresa como, por ejemplo, decidir cuanta deuda asumirá con terceros para financiar sus actividades o cuanto usará de sus propios recursos u otras fuentes de financiamiento; en este 
caso, no se trata de escoger un nivel de deuda arbitrario sino uno específico, aquel que optimice la estructura de capital de la empresa y minimice el costo de los recursos.

Entonces, la duda que surge es: ¿existe relación entre la elección de la forma en que una empresa se financia (estructura de capital) y el costo de obtener financiamiento (costo de capital)? La respuesta es sí, porque al elegir una estructura de capital se influye en la determinación del costo del capital que afectará los beneficios, ya que se estará afectando el peso relativo que recibirá cada uno de los costos de los recursos usados en el cálculo del costo promedio ponderado del capital (WACC en sus siglas en ingles).

Es claro que la elección entre deuda financiera y capital accionario determinará una estructura de pesos específicos que hará que el WACC aumente o disminuya.

Este enfoque analítico es de interés para el gerente puesto que la estructura optima del capital y el costo de los capitales estimados tendrá una fuerte incidencia en la evaluación de nuevos proyectos como la compra de nuevas máquinas o la creación de una nueva unidad de negocio.

Otro uso que se le puede dar a ambos conceptos es evaluar operaciones como fusiones, adquisiciones y valorización de empresas; así, por ejemplo, al valorar una empresa, uno de los métodos disponibles sugiere descontar los flujos de caja libres al costo del capital, en este caso el WACC.

Como la proporción optima del capital, junto a sus costos, sirve para calcular el WACC, primero se desarrollarán las definiciones y aplicaciones de la estructura del capital y, posteriormente, las del costo promedio ponderado del capital.

No obstante, antes hay que notar que una definición que guarda relación con la estructura y costo del capital que interesa conocer es el riesgo.

\section{financiero.}

El riesgo que enfrenta una empresa puede dividirse en riesgo de negocio y riesgo

El costo de capital, es el costo de los recursos usados por la empresa al operar; es un costo desde el punto de vista de la empresa pero es un rendimiento desde la visión de los proveedores de fondos, como los accionistas y los acreedores.

Esta tasa está compuesta, en principio, por: (a) el costo de la deuda (Kd), (b) la rentabilidad mínima exigida a las acciones (comunes - Re- y preferentes), y (c) la tasa impositiva marginal corporativa (T); expresadas en proporciones respecto de la deuda total.

Finalmente, el WACC resulta de ponderar los costos de los recursos usados por sus proporciones correspondientes respecto al capital total. 
Si la empresa se endeuda para financiar sus operaciones, se afirma que la empresa esta apalancada. En este caso, el WACC incorporara el beneficio del escudo fiscal por el pago de intereses de la deuda y se lo denominara "costo del capital después de impuestos".

Para distinguir la relación del endeudamiento y el WACC se revisa nuevamente la ecuación 8:

$$
W A C C=\frac{E R e+D R d(1-T)}{E+D}
$$

Donde:

E: Valor de mercado de patrimonio de la empresa.

D: Valor de mercado de la deuda de la empresa.

Re: Rentabilidad exigida por los accionistas.

Rd: Rentabilidad exigida por los acreedores (dueños de la deuda)

T: Impuesto a las utilidades que efectivamente paga la empresa, luego de aplicar la conciliación tributaria.

La figura 17 desagrega los componentes del costo de capital promedio ponderado (WACC):

De la figura 17, se desprende la ecuación:

\section{Capital $=$ Patrimonio + Deuda + Acciones Preferentes (12)}

A continuación, se explicaran cada uno de los conceptos que conforman el costo de capital de la empresa (figura 17).

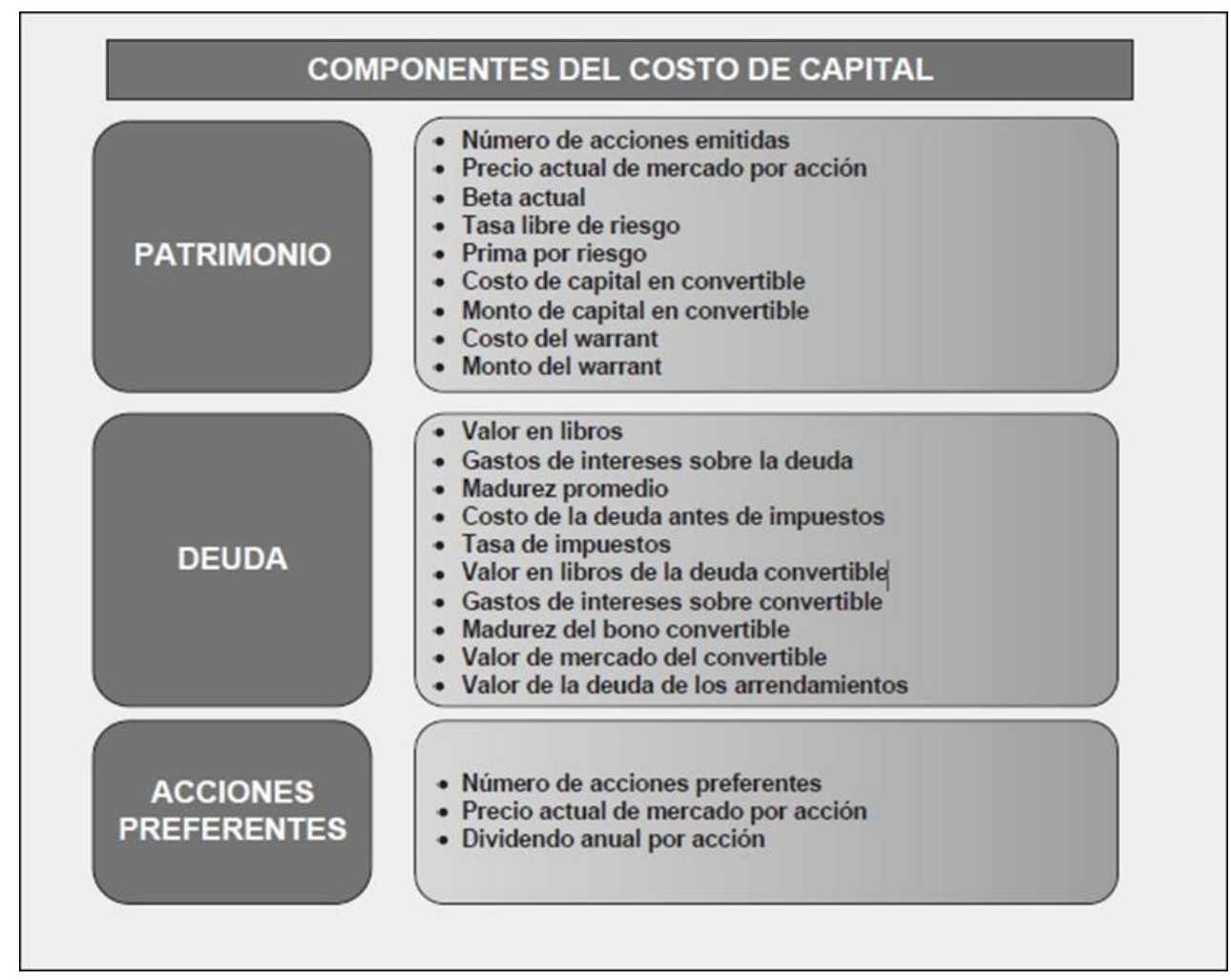

Figura 17 


\section{Patrimonio}

Comprende las acciones comunes, el capital en convertible y los warrants, las utilidades retenidas y las nuevas emisiones de acciones. Las acciones comunes son obligaciones que otorgan a su tenedor propiedad sobre una empresa. Además, representan derechos sobre una parte de los activos y las utilidades de esta. Por último, las acciones comunes usualmente brindan al propietario el derecho a votar en las juntas o asambleas de accionistas y a recibir dividendos.

Las acciones comunes ofrecen ventajas. Por ejemplo, al no tener vencimiento, eliminan cualquier obligación futura de cancelación lo que favorece su uso como medio de financiamiento.

Además permiten aumentar el financiamiento, mediante la emisión de más acciones comunes en el mercado, la base de capital contable aumentará, y así la posibilidad de obtener financiamiento a largo plazo, con más facilidad y a menor costo.

No obstante, financiarse por medio de acciones comunes trae la dilución del derecho a voto, además tiene un costo elevado puesto que el pago de dividendos no se deduce de impuestos e implican más riesgo que la deuda o las acciones preferentes. Cuando se trata de dilución se está refiriendo al efecto que trae aumentar la cantidad de acciones, que hace que la ganancia por acción disminuya.

Para calcular el costo de las acciones comunes se pueden usar uno los siguientes modelos cuyo uso dependerá de la situación en la que se encuentra. Se plantea el modelo de valoración de activos de capital (CAPM).

Donde:

$$
R e=R !+\beta R !-R !(13)
$$

Rf: Tasa del activo libre de riesgo propio (aquel que depende de características específicas del activo en el que se invierte). En la práctica se suele considerar los bonos de las deudas de los estados como activos libre de riesgo al creer que el estado nunca quebrará y tarde o temprano terminará honrando sus deudas. Se dice que este activo sólo incorporará el riesgo sistemático o riego base.

$\beta$ : Medida de sensibilidad del activo que se evalúa con respecto al mercado de valores de la economía en la que se encuentre.

Rm: Rentabilidad del índice bursátil del mercado de valores de la economía donde se esté realizando la valoración.

En la tabla 6 se representan el resto de componentes del valor patrimonial. 
Tabla 6

\begin{tabular}{|l|l|}
\hline Rubro & Valor \\
\hline+ Acciones Comunes & Número de Acciones comunes $\times$ Precio de Mercado Actual por Acción \\
\hline+ Warrants emitidos & Número de Warrants emitidos $\times$ Precio de Mercado Actual por Warrant \\
\hline+ Utilidades retenidas & Valor de las Utilidades Retenidas \\
\hline+ Acciones emitidas & Número de Acciones emitidas $\times$ Precio de Mercado Actual por Acción \\
\hline+ Capital Convertible & $\begin{array}{l}\text { Valor de la opción de conversión del bono }=\text { Valor nominal del bono convertible } \\
\times(\text { opción de compra/valor nominal del bono directo })\end{array}$ \\
\hline = EQUITY & VALOR DEL EQUITY \\
\hline
\end{tabular}

\section{Deuda}

La deuda comprende cualquier instrumento financiero que tiene un derecho contractual sobre los flujos de caja y activos de la empresa, crea pagos deducibles de impuestos, tienen un tiempo de vida determinado y tiene derechos de propiedad sobre los flujos de caja generados en periodos de operación y en bancarrota.

El costo de la deuda está determinado por los intereses que demanden los que aportan capital por esta vía. A este costo se le deducen los ahorros tributarios asociados con la deuda. El interés demandado estará en función del riesgo operativo del negocio y el grado de endeudamiento de la empresa.

Mientras mayor sea el riesgo operativo o el endeudamiento de la empresa, mayor será el interés demandado por los aportantes del capital. El costo de la deuda contraída con una institución financiera es igual a:

$R i=R d x 1-T(14)$

Donde:

Ri: Costo efectivo (para la empresa) de la deuda después de considerar el escudo fiscal.

Rd: Costo de la deuda, rendimiento pagado a los acreedores.

T: Impuesto sobre las utilidades gravables.

Los intereses de la deuda se deducen del pago de impuestos. Luego, ese es el motivo por el que se usará el costo de la deuda después de impuestos.

\section{Acciones preferentes}

Son títulos que otorgan un derecho mayor sobre los activos y las utilidades que las acciones comunes. Sus tenedores reciben dividendos antes que los accionistas comunes y tienen prioridad si la empresa entra en bancarrota y liquidación.

Usualmente, no dan derecho a voto. Debido a que no pueden ser tratadas realmente como deuda porque los dividendos que estas pagan no son deducibles de impuestos, y a que no pueden ser vistas como equivalentes a las acciones comunes debido a diferencias en los derechos sobre los flujos de caja y el control, las acciones preferentes son tratadas como un tercer componente del capital, en adición a las deudas y el capital patrimonial, para propósitos de analizar la estructura de capital y estimar el costo del capital. 
Son un tipo de obligación con características de acción y de deuda.

A semejanza de la deuda:

- Las acciones preferentes requieren un pago fijo; si la empresa no tiene el efectivo para pagar el dividendo, el dividendo es acumulado y pagado en un periodo donde existen suficientes utilidades.

- No confieren una parte del control de la empresa, y el privilegio de derecho a voto es restringido a emisiones que pueden afectar los derechos sobre los flujos de caja o activos de la empresa.

\section{A semejanza del capital accionario:}

- Los pagos a los tenedores de acciones preferentes no son deducibles de impuestos y son pagados de los flujos de caja después de impuestos.

- Las acciones preferentes no tienen una fecha de vencimiento cuando el valor nominal o facial es dado.

- En términos de prioridad, en el caso de bancarrota, los tenedores de acciones preferentes tienen que esperar hasta que los derechos de los tenedores de deuda han sido satisfechos antes de recibir cualquier porción de los activos de la empresa.

La mayoría de estas acciones se caracterizan por pagar un dividendo fijo a perpetuidad. Esto suele ser una ventaja ya que asegura al inversor este pago, independientemente que si la empresa obtiene o no beneficios en el periodo actual. Si no obtiene beneficios en este periodo que se traduzca en efectivo para pagar el dividendo, este es acumulado y pagado en un periodo posterior donde si tenga los beneficios suficientes para hacerlo.

Aunque contadores y agencias de calificación continúan tratando a las acciones preferentes como acciones, los compromisos fijos que crean pueden hacerlas más semejantes a la deuda. Las obligaciones creadas por las acciones preferentes son generalmente menos onerosas para la empresa que aquellas creadas por deuda, sin embargo, porque son generalmente acumulativas, no pueden causar incumplimiento y no tienen prioridad sobre los derechos de deuda en el caso de bancarrota.

Existen diferentes clases de acciones preferentes:

- Acciones que otorgan un dividendo fijo y con derecho a voto.

- Títulos que otorgan un dividendo fijo y sin derecho a voto.

- Acciones que brindan un dividendo normal y un porcentaje adicional fijo sobre el precio de la acción o sobre el dividendo. 
- Valores con derecho a voto plural, es decir en que una acción puede representar un número de votos (prohibidas en muchos mercados).

- Acciones que dan un derecho acumulativo o no sobre los dividendos y que puede ser por tiempo indeterminado o tiempo determinado.

Con los tres elementos descritos anteriormente se procede al cálculo del WACC, considerando todas las alternativas de financiamiento que puede tener una empresa.

El Costo Promedio Ponderado del Capital será igual al costo de capital de todas las fuentes de financiamiento que ocupa la empresa. Si las ponderaciones que se ocupan son históricas se presupone que la estructura de capital actual de la empresa es óptima y no se deben modificar. Si se emplea la ponderación marginal se infiere que la estructura de financiamiento no es la óptima, por lo cual se ha decidido modificar para poder llegar a la optimización de esta.

Los componentes individuales de capital deben combinarse. Además de los costos netos después de impuestos de los componentes individuales. Esta combinación se realiza a través del WACC. La estructura de capital es la mezcla de financiamiento a largo plazo que emplea la empresa. Por ejemplo, muy poca deuda a largo plazo, algo de capital preferente y una cantidad considerable de capital común.

Solo una combinación permite a la empresa maximizar su valor de mercado, la denominada "estructura óptima de capital".

Factores que afectan al WACC

Factores externos

- $\quad$ Nivel de las tasas de interés.

- Tasas tributarias.

Estos factores son exógenos a la empresa, es decir, son factores sobre los cuales las empresas no tienen control. De este modo, si las tasas de interés aumentan en la economía, el costo de la deuda crece y también el WACC; además, si la tasa tributaria aumenta, el costo de la deuda después de impuestos disminuye y el WACC también lo hará.

Factores internos

- $\quad$ Política de la estructura de capital.

- $\quad$ Política de dividendos.

- $\quad$ Política de inversión (activos y riesgo).

Si la empresa decide cambiar su estructura de capital esto afectara el costo del capital: si elige usar más deuda y menos capital accionario, las ponderaciones en el WACC cambiarán y este último disminuirá; sin embargo, si escoge más deuda crecerá el riesgo de deuda y de capital fijo, lo cual a su vez significará que los costos tenderán a anular los efectos del cambio de los pesos relativos. 
Sumado a lo anterior se puede concluir que el WACC está expuesto a muchos temas difíciles al momento de calcularlo como son:

- Fondos generados por depreciación: La fuente más abundante de capital para muchas empresas es la depreciación, pero esta tiene un costo y es aproximadamente igual al costo promedio ponderado de capital proveniente de las utilidades retenidas y de la deuda con bajo costo.

- Empresas de propiedad privada (que no cotizan en bolsa): Cuando se ha mencionado el costo de capital accionario en las sociedades anónimas, se ha concentrado en la tasa de rendimiento que quieren los accionistas; sin embargo, aún se discute sobre la manera de medir el costo de capital de una empresa que no cotiza en bolsa.

- Problemas de medición: Existen muchas dificultades prácticas para encontrar el costo de capital, es muy difícil conseguir información acerca de la prima de riesgo y el beta.

- Costos de capital con varios niveles de riesgo: Es muy difícil asignar tasas de descuento ajustadas al riesgo de los proyectos de presupuesto de capital con distinto grado de riesgo.

- Pesos en la estructura de capital: Es muy difícil establecer la estructura óptima de capital.

\section{Principales Errores en la Valoración de Empresas}

Según Fernández (2007) se pueden presentar los siguientes errores a la hora de valorar una compañía:

- $\quad$ Errores en el cálculo de la tasa de descuento que afecta al riesgo de la compañía:

a) Utilización de erróneas tasas libres de riesgo; por ejemplo utilización de la media histórica de la tasa libre de riesgo, o utilización como tasa libre de riesgo de la deuda del estado a corto plazo o cálculo inadecuado de la verdadera tasa libre de riesgo.

b) Cálculo erróneo de la beta; por ejemplo utilizando las betas históricas de la industria, o medias de betas de compañías similares o incluso betas históricas de la compañía cuando los resultados van en contra del sentido común, asumir que la beta calculada de datos históricos considera el riesgo país, utilizar fórmulas inadecuadas para apalancar o des apalancar la beta.

c) Estimaciones erróneas de la prima de riesgo de mercado; por ejemplo considerar que la prima de riesgo de mercado requerida es igual a la prima de riesgo histórica, o suponer que la prima de riesgo del mercado requerida es cero.

d) Cálculo erróneo del coste medio ponderado del capital (WACC); por ejemplo utilizar ratios entre capital y deuda diferentes a los que resultan de la valoración, utilizar va- lores contables de la deuda y del capital o fondos propios ara su estimación.

e) Erróneo tratamiento del riesgo país. 


\section{- $\quad$ Errores en el cálculo o estimación de los flujos de caja esperados:}

a) Errónea definición de los flujos de caja.

b) Olvidarse de proyectar el balance de situación, lo que afecta a determinados flujos de caja.

\section{- $\quad$ Errores en la estimación del valor terminal o valor residual:}

a) Utilización de flujos de caja inconsistentes cuando se estima el valor residual a perpetuidad.

b) Utilización de fórmulas específicas que no tienen sentido económico.

c) Utilizar medias aritméticas en lugar de medias geométricas para medir el crecimiento.

d) Asumir que la perpetuidad se inicia antes del período en que realmente debiera empezar.

e) Como puede apreciarse, demasiadas fuentes potenciales de error para que la valoración de una empresa se deje en manos inexpertas o con poca experiencia. Si ya es difícil valorar una compañía, al menos que dicha valoración sea realizada por expertos que mitiguen los riesgos de error.

\section{Nuevos ajustes y aproximaciones al modelo FCF}

En la literatura reciente de finanzas hay estudios que considerar que recursos intangibles producen un impacto en la generación de los resultados económicos de las organizaciones y que el Capital Humano es un inductor del valor y de la generación de resultados, por lo que ignorarlos en el proceso de valoración constituye una debilidad que es necesario corregir. También frente a los escenarios volátiles e inciertos considerar las opciones reales (OR), las cuales son posibles decisiones futuras, como alternativa para captar la incertidumbre generada por la dinámica empresarial y para flexibilizar el plan financiero establecido.

Se propone a las OR como la alternativa más viable para solucionar el problema de rigidez del modelo de Flujos de Caja Descontados que hemos construido empleando variables de CI. La utilización de las OR permite la simulación de distintos futuros. Las OR se definen como la extensión de la Teoría Financiera aplicada a las expectativas sobre activos reales en el futuro, es decir, la posibilidad de tomar una determinada decisión sobre el futuro de algunos hechos inciertos que pueden afectar los flujos (Amram, 2000) la cual se aprecia en la siguiente ecuación (15).

Valor de Empresa = Valor de Flujos de Caja Desconocidos + Valor de las OR

Azofra y Femández (1992) también señalan que en análisis financiero tradicional, entendiendo éste por exclusivamente cuantitativo, hay problemas relacionados con la selección de las variables más relevantes para el diagnóstico, la cuantificación de los indicadores, la inexistencia de una norma con la que confrontar éstos y la necesidad de considerar distintas 
variables simultáneamente, son algunas de la limitaciones y carencias que presenta el análisis tradicional de estados financieros (Azofra \& Femández, 1992).

A la superación de estos problemas, limitaciones y carencias se orienta el denominado moderno análisis financiero. El nuevo enfoque se apoya en la economía financiera de la empresa y en la utilización de técnicas estadísticas para el análisis e interpretación de la información financiera procedente no sólo de los estados contables, sino también de los mercados financieros o, incluso, las predicciones de los directivos sobre los resultados de la empresa. Sobre estas bases, el principal objetivo del modelo análisis financiero es la construcción formal de sistemas de información relacionados integralmente con la toma de decisiones financieras. La atención del análisis se dirige, pues, hacia las necesidades de información que requiere una dirección financiera que guía sus actuaciones y decisiones.

Los sistemas para medir los resultados en las empresas están entrenado en una tercera generación. Los sistemas de primera generación se basaban en el supuesto que los sistemas de medición sesgados tenían que complementarse con indicadores no financieros, incluyendo a los intangibles. Los sistemas de segunda generación usaron mapas de estrategia y/o éxito para tomar en consideración la naturaleza dinámica de la actividad empresarial y los procesos de transformación que vinculaban. Los sistemas de tercera generación vinculan explícitamente las dimensiones no financieras e intangibles de la actividad empresarial con la creación de un flujo de caja libre (Marr, Roos, Neely, Pike, \& Gupta, 2004).

De acuerdo a la noticia publicada en el diario EL COMERCIO ${ }^{6}$, la empresa mexicana Arca Continental, la segunda embotelladora de Coca Cola más grande de América Latina, anunció el 22 de Agosto del 2013 la compra de la mayoría de acciones del Holding Tonicorp de Ecuador, por un monto no divulgado. Según fuentes financieras, el acuerdo contempla la adquisición del 87\% de los títulos que están en manos de los accionistas mayoritarios. La firma indicó en un comunicado que esta operación está sujeta a la aprobación de diferentes organismos de ese país, entre ellas la autoridad de competencia.

Arca Continental destacó que esta inversión fortalecerá su competitividad en Suramérica, donde ya participa con éxito en Ecuador y Argentina, así como en el negocio de snacks (bocadillos) con la empresa Industrias Alimenticias Ecuatorianas (Inalecsa) Con una plantilla de más de 3.000 trabajadores, Tonicorp es uno de los grupos más importantes en el sector del consumo, con ventas totales por 308 millones UM en el 2012.

Tonicorp® es un holding formado por empresas líderes de nuestro país: Industrias Lácteas Toni, Plásticos Ecuatorianos y Dipor. Estás sólidas compañías han decidido abrirse a los ecuatorianos, para seguir creciendo junto a quienes desde hace más de 40 años acompañan su exitosa trayectoria.

El presidente de grupo ecuatoriano, Francisco Alarcón, señaló que este acuerdo proporcionará a Tonicorp la oportunidad de potenciar sus marcas, así como continuar el fuerte crecimiento que ha mantenido por décadas. Arca Continental está presente desde 2012 en el mercado mexicano de lácteos a través de Santa Clara, empresa en la que participa en conjunto

\footnotetext{
${ }^{6} \mathrm{http}: / /$ www.elcomercio.com/negocios/Embotelladora-Arca-Continental-ecuatoriano-TonicorpEmpresas_0_979102289.html.
} 
con la Compañía Coca-Cola y otros embotelladores mexicanos. Cuenta con una franquicia para producir y distribuir bebidas de The Coca-Cola Company, además de botanas saladas de las marcas Bokados en México, Inalecsa en Ecuador y Wise en Estados Unidos. En 2011, las embotelladoras mexicanas Arca y Grupo Continental se fusionaron para formar la segunda empresa embotelladora de Coca Cola en América Latina. En abril de este año, el grupo mexicano anunció inversiones por unos 341 millones de UM en la expansión de sus negocios en México, Ecuador, Argentina y Estados Unidos.

Según el Prospecto de Oferta Pública que tiene proyecciones de TONICORP se muestra el Cálculo del precio de acción realizado por la Casa de Valores que comercializó las acciones en la siguiente figura:

\begin{tabular}{|c|c|c|c|c|c|}
\hline & & TONI & PESA & DIPOR & \\
\hline \multirow[t]{6}{*}{ Utilidades netas } & 2011 & $11.222 .153,25$ & $3.675 .378,62$ & $4.919 .860,16$ & 19.817.392,03 \\
\hline & 2012 & $11.962 .324,23$ & $3.587 .426,34$ & $5.767 .345,17$ & $21.317 .095,73$ \\
\hline & 2013 & $13.787 .859,46$ & $4.116 .079,94$ & $6.512 .898,94$ & $24.416 .838,34$ \\
\hline & 2014 & $16.049 .736,67$ & $4.799 .166,27$ & $7.325,793,63$ & $28.174 .696,57$ \\
\hline & 2015 & $18.571 .573,62$ & $5.527 .520,96$ & $8.201 .158,72$ & $32.300 .253,31$ \\
\hline & 2016 & $21.343 .146,80$ & $6,074,633,52$ & $9.146,682,08$ & $36.564 .462,40$ \\
\hline \multirow[t]{6}{*}{ Dividendos en Efectivo según Paquete Inversor } & 2011 & $11.222 .153,25$ & $2.185 .183,24$ & $4.919 .860,16$ & 18.327.196,65 \\
\hline & 2012 & $11.962 .324,23$ & $963.780,99$ & $5.767,345,17$ & $18.693 .450,39$ \\
\hline & 2013 & $13.787 .859,46$ & $1.372 .026,65$ & $6.512 .898,94$ & $21.672 .785,04$ \\
\hline & 2014 & $16.049 .736,67$ & $2.459 .218,88$ & $7.325 .793,63$ & $25.834 .749,18$ \\
\hline & 2015 & $18.571 .573,62$ & $3.370 .009,42$ & $8.201 .158,72$ & $30.142 .741,77$ \\
\hline & 2016 & $21.343 .146,80$ & $5.798 .272,14$ & $9.146 .682,08$ & $36.288 .101,02$ \\
\hline
\end{tabular}

HOLDING

\begin{tabular}{|c|c|c|c|c|c|c|c|}
\hline Aporte a Holding luego de Capitalización de Patrimonio & $41.355,130,11$ & $\begin{array}{r}42.845 .325,49 \\
1.490 .195,37\end{array}$ & $\begin{array}{r}45.468 .970,83 \\
2.623 .645,34\end{array}$ & $\begin{array}{r}48.213 .024,12 \\
2.744 .053,29\end{array}$ & $\begin{array}{r}50.552 .971,51 \\
2.339 .947,39\end{array}$ & $\begin{array}{r}52.710 .483,05 \\
2.157 .511,54\end{array}$ & $\begin{array}{r}52.986 .844,43 \\
276.361,38\end{array}$ \\
\hline & & 2011 & 2012 & 2013 & 2014 & 2015 & 2016 \\
\hline Ingresos por Dividendos en Efectivo Recibidos por la Holding & & $18.327 .196,65$ & $18.693 .450,39$ & $21.672 .785,04$ & $25,834,749,18$ & $30.142 .741,77$ & $36.288 .101,02$ \\
\hline Tasa de Descuento & $13,00 \%$ & & & & & & \\
\hline Tasa de Crecimiento del Dividendo & $14,64 \%$ & & & & & & \\
\hline Tasa de Descuento Deflactada con la Tasa de Crecimiento & $11,34 \%$ & & & & & & \\
\hline
\end{tabular}

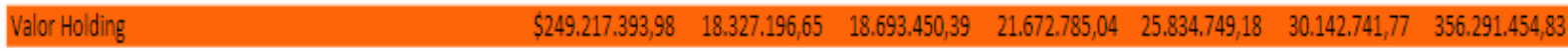
PRECIO DE LA ACCION A VALORACION

Figura 18: Cálculo del Precio de Acción Holding TONICORP7

\footnotetext{
${ }^{7}$ Esta información esta respalda en la página de TONI donde se puede bajar información financiera actualizada en http://www.tonicorp.com/informacion- financiera.aspx
} 


\section{tonicorp}

Holding Tonicorp S.A. y Subsidiarias

Estado Consolidado de Resultados Integrales

AMo que terminó el 31 de diciembre de 2012, con cifras comparativas de 2011

(Expresado en Dólares de los Estados Unidos de América - USS)

Ventas netas
Costo de las ventas

Ctros ingresos

Gastos de ventas, generales y administrativos

Otros gastos

Resultado de actividades de operacion

Costo financiero:

Intereses pagados

Intereses ganados

Costo financiero, neto

Utidad antes de impuesto a la renta

Impuesto a la renta

Utildad neta

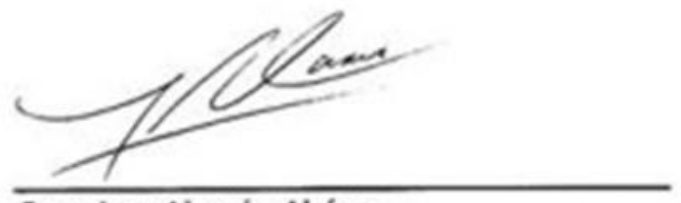

Francisco Alarcón Alcívar

Gerente General
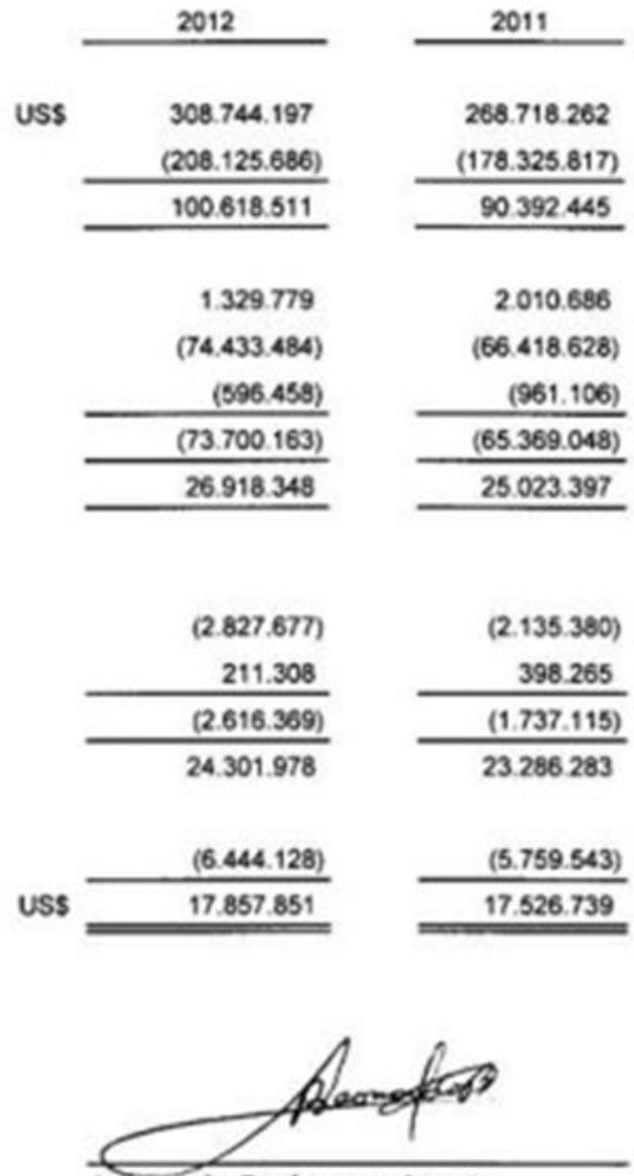

Leonardo Beckmann Acosta

Contador

Figura 19 
En el 2001 se creó Toni Corp cuyo unico objeto es la tenencia de acciones de las empresas del Grupo Toni, la información del prospecto de emisión en la figura 20 muestra la siguiente proyecccion de reparto de dividendos.

\begin{tabular}{|c|c|c|c|c|c|c|}
\hline PESA & 2011 & 2012 & 2013 & 2014 & 2015 & 2016 \\
\hline Porcentaje Reparto Efectivo & $59.45 \%$ & $26.87 \%$ & $33.33 \%$ & $51.24 \%$ & $60.97 \%$ & $95.45 \%$ \\
\hline Dividendo Efectivo Proyectado & $2,185,183$ & 963,781 & $1,372,027$ & $2,459,219$ & $3,370,009$ & $5,798,272$ \\
\hline Dividendo Acción Proyectado & $1,490,195$ & $2,623,645$ & $2,744,053$ & $2,339,947$ & $2,157,512$ & 276,361 \\
\hline TONI & 2011 & 2012 & 2013 & 2014 & 2015 & 2016 \\
\hline Porcentaje Reparto Efectivo & $100.00 \%$ & $100.00 \%$ & $100.00 \%$ & $100.00 \%$ & $100.00 \%$ & $100.00 \%$ \\
\hline Dividendo Efectivo Proyectado & $11,222,153$ & $11,962,324$ & $13,787,859$ & $16,049,737$ & $18,571,574$ & $21,343,147$ \\
\hline Dividendo Acción Proyectado & $\cdot$ & - & - & - & - & $\cdot$ \\
\hline DIPOR & 2011 & 2012 & 2013 & 2014 & 2015 & 2016 \\
\hline Porcentaje Reparto Efectivo & $100.00 \%$ & $100.00 \%$ & $100.00 \%$ & $100.00 \%$ & $100.00 \%$ & $100.00 \%$ \\
\hline Dividendo Efectivo Proyectado & $4,919,860$ & $5,767,345$ & $6,512,899$ & $7,325,794$ & $8,201,159$ & $9,146,682$ \\
\hline Dividendo Acción Proyectado & - & $\cdot$ & - & - & $\cdot$ & $\cdot$ \\
\hline
\end{tabular}

Figura 20: Caso de estudio

A continuación se realizará un ejemplo sencillo de la evaluación de estados financieros, proyección de flujos de caja para la empresa y para los accionistas, cálculos de las tasas de interés promedio ponderado y la rentabilidad de los accionistas, para luego determinar los valores respectivos de mercado de la empresa como un todo y para los accionistas.

Grifine $^{8}$, la empresa elegida es una empresa ecuatoriana que cotiza en el mercado de valores ecuatoriano. Al ser el mercado de valores ecuatoriano no muy desarrollado, las acciones que ahí cotizan tienen poca o nula evolución a través del tiempo, lo que genera que el precio no sea representativo de la valoración que los inversionistas están dándole a la empresa.

Por lo anterior, es que el método sugerido para valoración será flujo de caja descontados para considerar lo que se cree afectará a la empresa en el futuro y a cada una de sus cuentas. El modelo de Gordon y Shapiro no podría ser utilizado porque al no tener una evolución del precio de las acciones de la empresa y política de dividendos claramente establecida, no se pudiese seguir el supuesto de un crecimiento constante de los dividendos como una señal creíble de las utilidades proyectadas de la empresa.

Uno de los primeros pasos que se debe realizar es un análisis detallado de los estados financieros, Estado de Resultados, Flujo de Caja y Balance General. En esta ocasión al ser un ejercicio netamente académico se asumirá que los supuestos que se utilicen para la proyección

\footnotetext{
${ }^{8}$ los datos que se utilizarán para el caso de estudio han sido tomadas del prospecto de oferta pública ii de obligaciones de Griffine, disponible en http://sigcv.mundobvg.com/opciones\%20de\%20inversion/renta\%20fija/prospectos/grifine\%20s.a/obligaciones/pros pecto\%202.pdf
} 
han salido como producto de un análisis horizontal, vertical y de mercado de la información financiera de la empresa.

La Compañía tiene como objeto social dedicarse a importar, exportar, comprar, vender al por mayor y menor, distribuir, arrendar, intermediar, producir, fabricar / instalar; dar mantenimiento y reparar toda clase de equipos, accesorios, instrumentos y partes de todo tipo de materiales y acabados de construcción.

\section{GRIFINE S.A.}

(Guayaquil - Ecuador)

ESTADO DE RESULTADO INTEGRAL

AÑOS TERMINADOS EL 31 DE DICIEMBRE DEL 2011 Y 2010

(Expresado en dólares)

INGRESOS OPERACIO
VENTAS
Ventas $12 \%$
Total Ventas
Total Ingresos Operacion
(-) Costos y Gastos Opera
Costo de Ventas y Producció
Utilidad Bruta
(-) Gastos Operacionales
Gastos de Administración
Gastos de Ventas
Gastos Financieros
Utilidad Operacional

(+) Otros Ingresos No Operacionales Otros lngresos

Total Otros Ingresos No Operacionales

(-) Otros Gastos No Operaciodales Otros Gastos

Total Otros Gastos No Operacionales

Utilidad o Perdida antes de Impuestos

(-) $15 \%$ Participación Trabajadores

(-) $24 \%$ impuesto a la Renta

(-) $10 \%$ Reserva Legal

Utilidad o Perdida del Ejercicio $\underline{2011} \underline{2010}$

$\frac{\frac{15.687 .442,95}{15.687 .442,95}}{15.687 .442,95} \frac{12.395 .067,38}{12.395 .067,38}$

$\frac{10.027 .422,01}{\mathbf{5 . 6 6 0 . 0 2 0 , 9 4}} \frac{8.432 .356,81}{\mathbf{3 . 9 6 2 . 7 1 0 , 5 7}}$

$1.257 .088,11 \quad 1.112 .353,80$

$1.482 .739,13 \quad 1.694 .344,67$

$\frac{352.728,36}{\mathbf{2 . 5 6 7 . 4 6 5 , 3 4}}-\frac{384.802,15}{771.209,95}$

$\frac{15.298,86}{15.298,86}-\frac{14.360,74}{14.360,74}$

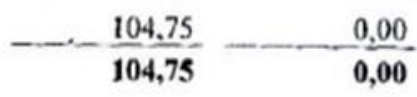

2.582.659,45 $\quad 785.570,69$

$387.398,92 \quad 117.835,60$

$542.466,58 \quad 211.005,27$

$\frac{165.279,39}{1.487 .514 .56}-\frac{45.672,98}{411.056 .84}$

En la figura 21 se presenta el Estado de Resultados para los años 2010 y 2011. 
Supuestos de valoración:

a) La información financiera obtenida está a finales del 2011, por lo que se asumirá como horizonte de planeación a partir del 2012.

b) Las ventas mantendrán un crecimiento constante a través del horizonte de planeación, cinco años de proyección y a partir del sexto año una perpetuidad. El crecimiento estimado será del $20 \%$ para estabilizarse a perpetuidad en un $10 \%$.

c) Los costos de ventas mantendrán el mismo porcentaje de participación histórico con respecto a las ventas.

d) Los gastos de administración crecerán a su tasa histórica y los de ventas serán un porcentaje con respecto a las ventas totales.

e) Los gastos financieros se calcularán en función de las estimaciones de deudas financieras.

f) Las cuentas otros ingresos y otros egresos se asumirán constantes como porcentaje de participación con respecto a los ingresos por ventas.

g) Se trabajará con una participación de trabajadores del 15\% e impuesto a la renta del $22 \%$ que aplica en Ecuador desde el 2012.

h) Se han estimado los valores de amortización de deuda y necesidades operativas de fondos en función de los estados financieros de la empresa. En la práctica, éstos deberían incluir las expectativas y estrategias que la empresa considere utilizará en el futuro.

i) Se piensa vender activos improductivos en el 2014 por un valor estimado de 2 millones de UM y adquirir a inicios del 2015 equipamiento por un total proyectado de 12 millones de UM. La inversión será financiada con préstamo a la Corporación Financiera Nacional (CFN) con un préstamo a 10 años plazo a una tasa de interés del 9\%.

j) Los valores de depreciaciones y cuentas incobrables son resultado de información existente en los estados financieros.

A continuación en la tabla 8 se presenta el Estado de Resultados proyectado y convertido en Flujo de Caja del accionista finalmente. Este estado financiero parte del hecho de considerar que la empresa está endeudada y que además del riesgo de incumplimiento incorporado, también se obtiene beneficios por el incremento de un gasto deducible. En la tabla 8 se puede apreciar como bajan los impuestos a raíz de que la empresa aumenta sus gastos financieros. Esa disminución en el pago de impuestos es la que se conoce como escudo fiscal de la deuda.

En la tabla 9 se presenta el Flujo de Caja para la empresa, donde el objetivo es evaluar los flujos generados por el negocio mismo sin considerar los efectos de la estructura de capital de la empresa sino solamente los creadores de valor propios de su actividad principal, por este motivo se parte de la utilidad antes de intereses e impuestos, asumiendo que la empresa no está 
endeudada calculando los impuestos, participación de trabajadores y reserva legal que se deberían haber cancelado si la empresa no hubiese estado endeudada.

En el esquema de flujo de caja de la empresa (Flujo de caja libre), los valores de participación de trabajadores, impuesto a la renta y reserva legal, no constituyen los verdaderos valores que debe cancelar y proporcionar respectivamente la empresa, el ejercicio es netamente para evaluar la totalidad de los flujos de caja que la empresa podría generar para todos sus inversionistas, es decir acreedores y accionistas considerando que no tiene beneficios adicionales por estar endeudada.

\section{Tabla 8}

\begin{tabular}{|c|c|c|c|c|c|}
\hline & 2012 & 2013 & 2014 & 2015 & 2016 \\
\hline Ventas & $18.824 .931,54$ & $22.589 .917,85$ & $27.107 .901,42$ & $32.529 .481,70$ & $39.035 .378,04$ \\
\hline (-) Costo de ventas & $13.930 .449,34$ & $16.716 .539,21$ & $20.059 .847,05$ & $24.071 .816,46$ & $28.886 .179,75$ \\
\hline (=) Ut. Bruta & $4.894 .482,20$ & $5.873 .378,64$ & $7.048 .054,37$ & $8.457 .665,24$ & $10.149 .198,29$ \\
\hline Gastos de adm. & $1.382 .796,92$ & $1.521 .076,61$ & $1.673 .184,27$ & $3.040 .502,70$ & 4.424.552,97 \\
\hline Gastos de ventas & $2.258 .991,78$ & $2.710 .790,14$ & $3.252 .948,17$ & $3.903 .537,80$ & $4.287 .698,65$ \\
\hline Otros ingresos & $22.589,92$ & $27.107,90$ & $32.529,48$ & $39.035,38$ & $46.842,45$ \\
\hline Otros gastos & 159,09 & 190,91 & 229,09 & 274,90 & 329,89 \\
\hline Gastos financieros & $414.265,98$ & $398.500,57$ & $379.654,98$ & $1.444 .980,56$ & $1.313 .945,12$ \\
\hline Ut. Antes & & & & & \\
\hline impuestos & $860.858,34$ & $1.269 .928,31$ & $1.774 .567,34$ & $107.404,65$ & $169.514,12$ \\
\hline (-) $15 \%$ part. Trabaj. & $129.128,75$ & $190.489,25$ & $266.185,10$ & $16.110,70$ & $25.427,12$ \\
\hline (-) $24 \%$ Impto. Renta & $160.980,51$ & $237.476,59$ & $331.844,09$ & $20.084,67$ & $31.699,14$ \\
\hline (-) $10 \%$ Reserva legal & $57.074,91$ & $84.196,25$ & $117.653,81$ & $7.120,93$ & $11.238,79$ \\
\hline$(=\quad$ Utilidad del & & & & & \\
\hline ejercicio & $513.674,17$ & $757.766,22$ & $1.058 .884,33$ & $64.088,35$ & $101.149,07$ \\
\hline (+) Depreciación & $314.600,00$ & $302.300,34$ & $287.900,34$ & $1.267 .549,34$ & $1.234 .097,23$ \\
\hline $\begin{array}{l}(+) \quad \text { Cuentas } \\
\text { incobrables }\end{array}$ & $564.747,95$ & $677.697,54$ & $813.237,04$ & $975.884,45$ & $1.171 .061,34$ \\
\hline (-) Amortización & & & & & \\
\hline $\begin{array}{l}\text { capital } \\
(+) \text { Préstamo CFN }\end{array}$ & $814.652,12$ & $912.000,56$ & $\begin{array}{l}990.876,12 \\
12.000 .000,00\end{array}$ & $1.209 .876,12$ & $1.256 .574,34$ \\
\hline $\begin{array}{ll}(-) & \text { Compra } \\
& \text { activos fijos }\end{array}$ & & & $12.000 .000,00$ & & \\
\hline (+) Venta activos fijos & & & $2.000 .000,00$ & & \\
\hline$(-)$ NOF & $376.498,63$ & $451.798,36$ & $542.158,03$ & $650.589,63$ & 780.707,56 \\
\hline (=) FC accionistas & $201.871,37$ & $373.965,18$ & $2.626 .987,57$ & $447.056,39$ & $469.025,74$ \\
\hline
\end{tabular}

En el flujo de caja libre se podrá observar que no constan valores para gastos financieros y amortización de capital debido a que no se considera el efecto endeudamiento.

\section{Tabla 9}




\begin{tabular}{cccccc}
\hline & 2012 & 2013 & 2014 & 2015 & 2016 \\
\hline Ventas & $18.824 .931,5$ & $22.589 .917,85$ & $27.107 .901,4$ & $32.529 .481,7$ & $39.035 .378,0$ \\
(-) Costo de ventas & 4 & & 2 & 0 & 4 \\
& $13.930 .449,3$ & $16.716 .539,21$ & $20.059 .847,0$ & $24.071 .816,4$ & $28.886 .179,7$ \\
(=) Ut. Bruta & 4 & & 5 & 6 & 5 \\
& $4.894 .482,20$ & $5.873 .378,64$ & $7.048 .054,37$ & $8.457 .665,24$ & $10.149 .198,2$ \\
Gastos de adm. & & & & & 9 \\
Gastos de ventas & $1.382 .796,92$ & $1.521 .076,61$ & $1.673 .184,27$ & $3.040 .502,70$ & $4.424 .552,97$ \\
Otros ingresos & $2.258 .991,78$ & $2.710 .790,14$ & $3.252 .948,17$ & $3.903 .537,80$ & $4.287 .698,65$ \\
Otros gastos & $22.589,92$ & $27.107,90$ & $32.529,48$ & $39.035,38$ & $46.842,45$ \\
Gastos financieros & 159,09 & 190,91 & 229,09 & 274,90 & 329,89 \\
(=) Ut. Antes intereses e & $1.275 .124,32$ & $1.668 .428,88$ & $2.154 .222,32$ & $1.552 .385,21$ & $1.483 .459,24$ \\
impuestos & & & & & \\
(-) 15\% part. Trabaj. & $191.268,65$ & $250.264,33$ & $323.133,35$ & $232.857,78$ & $222.518,89$ \\
(-) 24\% Impto. Renta & $238.448,25$ & $311.996,20$ & $402.839,57$ & $290.296,03$ & $277.406,88$ \\
(-) 10\% Reserva legal & $84.540,74$ & $110.616,83$ & $142.824,94$ & $102.923,14$ & $98.353,35$ \\
(=) Utilidad del ejercicio & $760.866,68$ & $995.551,51$ & $1.285 .424,46$ & $926.308,25$ & $885.180,13$ \\
(+) Depreciación & $314.600,00$ & $302.300,34$ & $287.900,34$ & $1.267 .549,34$ & $1.234 .097,23$ \\
(+) Cuentas incobrables & $564.747,95$ & $677.697,54$ & $813.237,04$ & $975.884,45$ & $1.171 .061,34$ \\
(-) Amortización capital & & & & & \\
(+) Préstamo CFN & & & $12.000 .000,0$ & & \\
(-) Compra activos fijos & & & 0 & & \\
(+) Venta activos fijos & & & $12.000 .000,0$ & & \\
(-) NOF & & & 0 & & \\
(=) FC empresa (FCL) & $1.263 .716,00$ & $1.523 .751,03$ & $3.844 .403,81$ & $2.519 .152,41$ & $2.509 .631,14$ \\
\hline
\end{tabular}

Ahora se precederá a calcular las tasas de interés de los accionistas (Re para lo cual se utilizará el modelo CAPM mencionado durante el documento) y la rentabilidad de la empresa según CCPP (WACC).

Al no ser una empresa que cotiza activamente en el mercado de valores, uno de los limitantes será el cálculo del Beta que para la misma empresa no será factible obtener. En estos casos se puede utilizar el beta de empresas comparables para lo cual se utilizará investigaciones realizadas para diferentes economías, información proporcionada por autores reconocidos en el medio como Aswath Damodaran ${ }^{9}$ que por medio de su página web presenta entre otros datos, betas para diferentes sectores económicos y para economías emergentes, categoría en la que caería Ecuador.

Se debe recordar las ecuaciones que se van a utilizar:

$$
W A C C=E R e+D R d(1-T) E+D(8)
$$

\footnotetext{
${ }^{9}$ Información obtenida de www.damodaran.com, en la sección Update Data, Levered and Unlevered Betas by Industries, información para Mercados emergentes. El sector comparable con el de la empresa ecuatoriana sería "Construcción" con un beta desapalancado de 0,74
} 


$$
R e=R !+\beta R !-R !
$$

Para el cálculo de la Rf se recurrirá al desglose de la tasa libre de riesgo para inversiones en la economía ecuatoriana. Una metodología es partir del activo libre de riesgo de Estados Unidos, bono a 10 años plazo que actualmente se encuentra en $2,94 \%{ }^{10}$ y sumarle el riesgo país de Ecuador (metodología del EMBI) que se encuentra en 631 puntos. $^{11}$

El siguiente paso debería ser calcularse la rentabilidad del índice bursátil, otra limitación al no tener un índice representativo del mercado de valores del Ecuador por la falta de movimiento del mercado. En estos casos se recomienda trabajar con una prima estándar que investigaciones sugeridas para mercados financieros refieren un $9 \%$ como la diferencia entre el activo libre de riesgo y la inversión en acciones.

Por último, se debe calcular la beta apalancada de la empresa, es decir tomar el beta desapalancado (sin deuda) obtenida del sector construcción y agregarle el riesgo financiero de GRIFINE para trabajar de obtener un beta representativo del sector en que se encuentra la empresa (Riesgo operativo) y su nivel de endeudamiento (Riesgo financiero). La fórmula respectiva es la presentada en la ecuación 15:

Donde:

$\beta a=$

$(1-L T)(16)$

Ba: Beta desapalancado, (sin deuda) que solo refleja el riesgo del negocio en el que se encuentra la empresa.

B: Beta apalancado que incluye tanto riesgo financiero como riesgo operativo. L: Nivel de endeudamiento, razón de deuda.

$\mathrm{T}$ : Tasa de impuesto a la renta.

La tabla 10 presenta la información resumida con el respectivo cálculo de la rentabilidad de los accionistas. Para el cálculo del beta apalancado (beta con deuda se consideró nivel de impuesto a la renta $22 \%$ y nivel de endeudamiento $34 \%$ ).

Tabla 10

\begin{tabular}{cc}
\hline Rf usa & $2,94 \%$ \\
\hline P.R. Ecuador & $6,31 \%$ \\
Rf Ecuador & $9,25 \%$ \\
Rm-Rf & $9 \%$ \\
B sin deuda & 0,74 \\
\hline
\end{tabular}

\footnotetext{
${ }^{10}$ www.yahoo.finance.comdato actualizado al 08 de septiembre de 2013.

${ }^{11}$ http://www.bce.fin.ec/resumen_ticker.php?ticker_value=riesgo_pais información actualizada por el Banco Central del Ecuador al 19 de agosto de 2013.
} 


\begin{tabular}{cc}
\hline B con nivel de deuda de la empresa & 1,04 \\
$\operatorname{Re}$ & $18,61 \%$ \\
\hline
\end{tabular}

Finalmente se procederá a calcular la tasa de la empresa, considerando su estructura de capital. La estructura de capital ha sido obtenida en función de su razón de deuda tomada de sus estados financieros. La tasa de la deuda se calculó como promedio ponderado de las deudas que generan intereses para la empresa. La información resumida se presenta en la tabla 11:

Tabla 11

\begin{tabular}{ll}
\hline $\mathrm{L}$ & $34 \%$ \\
\hline$(1-\mathrm{L})$ & $66 \%$ \\
$\mathrm{~T}$ & $22 \%$ \\
$\mathrm{Rd}$ & $11,24 \%$ \\
$\mathrm{Re}$ & $18,61 \%$ \\
$\mathrm{WACC}$ & $15,26 \%$ \\
\hline
\end{tabular}

Con estas tasas de interés se procederá a calcular los valores de mercado de la empresa y de la parte que les corresponde a los accionistas. Se recuerda que las ecuaciones a ser utilizadas son:

$$
\begin{gathered}
V E=F C ! \\
(1+R) !+\quad F C !(1+R) !+\cdots+F C !+V R !(5) \\
V R=F C !(1+g)=F C ! ! !(6) \\
(R-g) \quad R-g
\end{gathered}
$$

En la tabla 12 se presenta el resumen del valor presente para cada uno de los primeros cinco años de proyección. Luego se calculó el flujo de caja del periodo seis considerando una tasa de crecimiento del $10 \%$ para terminar con el cálculo del valor residual con la mencionada tasa.

\begin{tabular}{lllll}
\multicolumn{5}{c}{ Tabla 12 } \\
\hline Periodo & FC acc. & FCL & VA Fcacc $(18,61 \%)$ & VA FCL $(15,26 \%)$ \\
\hline 2012 & $201.871,37$ & $1.263 .716,00$ & $170.197,60$ & $1.096 .404,65$ \\
2013 & $373.965,18$ & $1.523 .751,03$ & $265.820,55$ & $1.146 .982,47$ \\
2014 & $2.626 .987,57$ & $3.844 .403,81$ & $1.574 .323,94$ & $2.510 .690,35$ \\
2015 & $447.056,39$ & $2.519 .152,41$ & $225.879,64$ & $1.427 .381,23$ \\
2016 & $469.025,74$ & $2.509 .631,14$ & $199.797,55$ & $1.233 .720,60$ \\
2017 (g=10\%) & $515.928,32$ & $2.760 .594,25$ & & \\
Valor Residual & $5.992 .198,82$ & $52.482 .780,43$ & $2.552 .581,90$ & $25.800 .240,77$ \\
Valor Mercado & & & $4.988 .601,17$ & $33.215 .420,08$ \\
\hline
\end{tabular}

El valor de mercado de la empresa como un todo según este ejemplo sencillo y con base académica más que real, sería de 33.215.420,08 UM considerando una tasa de interés de 15,26\%. 
Este valor sería el posible valor a considerar para calcular precios de acciones de futuras emisiones y si se desea poner a la venta la empresa este podría ser considerada como el valor base para la negociación.

En lo que respecta al valor de mercado de la empresa en aquella parte que solamente corresponde a los accionistas, su valor sería de 4.988.601,17 UM considerando una tasa de $18,61 \%$. Este valor es solamente el valor de mercado del patrimonio de los accionistas considerando su actual costo de oportunidad de inversión. 


\section{Reflexiones y Conclusiones}

- De la revisión de la literatura ha quedado claro que lo estratégico es lo que agrega valor, es decir, que produce FCL. Administrar el valor de una empresa debería ser la clave de estrategias ganadoras.

- Si bien se afirma que Finanzas y Dirección Estratégica son dos disciplinas de la empresa que deberían mantener una estrecha relación en la práctica profesional. Se observó que la formulación estratégica no está conectada con los modelos como el FCL. Como los señala Porter hay que redescubrir el valor de la estrategia conectándola con la generación de valor

- ¿Qué reflexiones sobre el crecimiento y la generación de valor deberían hacer en un ejercicio de formulación estratégica?

- Consideramos que muy importante incluir el análisis factores clave inductores en el proceso de creación de valor. Toda estrategia debería de analizarse a partir de la diferencia entre el incremento marginal del valor de las acciones de la firma consecuencia de la adopción de aquella y su costo de implementación. La estimación de dicha diferencia requeriría la utilización de modelos de valoración como los que hemos visto en estar artículo

- Es posible con los conocimientos de finanzas, razonamiento lógico y el conocimiento de los escenarios cuantificar las correspondientes repercusiones estratégicas de las decisiones.

- La asociación entre tasa de crecimiento y tasa de ganancias del capital ha quedado mostrado en el modelo de Gordon y Shapiro. Una empresa con tasas de crecimiento muy altas tienden a no entregar los dividendos y reinvertir con la empresa para continuar con la curva de crecimiento.

- Hay un aparente dilema: entre valor de accionistas y valor de la empresa. En nuestro criterio la prioridad siempre debería ser la maximización de la empresa, ya que eso es lo que el continuidad a los flujos futuros.

- Debemos buscar siempre la maximización del valor de la empresa. Habría de estilos CEOS. 


\section{Bibliografía}

Azofra, V., \& Femández, A. (1992). Evolución reciente de la moderna teoría financiera. Anales de Ciencias Económicas y Empresariales, NQ7, 111-126.

Blank, L., \& Tarquin, A. (2002). Ingeniería Económica. México D.F.: McGraw Hill. Court Monteverde, E. (2012). Finanzas Corporativas. Buenos Aires: Cengage Learning.

Damodaran, A. (2005). Valuation Approaches and Metrics: A Survey of the Theory. Hanover: Foundations and Trends in Finance.

Damodaran, A. (2001). The Dark Side of Valuation. Prentice Hall. Fernández, P. (1998). Valoración de Empresas. Barcelona: Gestión 200.

Fernández, P. (noviembre de 2008). IESE Business School. Recuperado el 30 de agosto de 2013, de Universidad de Navarra: http://ssrn.com/abstract=1266623

Fernández, P. (2008). Métodos de Valoración de Empresas. CIIF, 52.

Gallegos Muñoz, C., \& Medina Giacomozzi, A. (2011). Determinación del valor económico añadido: un modelo alternativo. Contabilidad y Negocios, 18.

López Lubian, F., \& De Luna Butz, W. (2002). Finanzas Corporativas en la práctica. Madrid: McGraw Hill.

Marr, B., Roos, G., Neely, A., Pike, S., \& Gupta, O. (2004). Hacia la tercera generación en la medición de resultados. Revista de Contabilidad y Dirección, 1, 31-46.

Milla Gutiérrez, A., \& Martínez Pedrós, D. (s.f.). Altair Consultores. Recuperado el Agosto de 2013, de http://www.altairconsultores.com/images/stories/publicaciones/Libro_Valoracion.pdf

Modigliani, F. y. (1958). The Cost of Capital, Corporation Finance and the Theory. American Economic Review, 261-297.

Palenzuela, V. A., \& Herrero, G. d. (2008). La huella indeleble de Modigliani y Miller: MM.

Boletín de estudios económicos 63, 373-401.

Pereyra, T. M. (2008). Valoración de empresas: Una revisión de métodos actuales. Documento de trabajo No. 41, Facultad Administración y Ciencias Sociales, Universidad ORT Uruguay, 34.

Romero, L. Á. (2010). Principios de contabilidad. McGraw Hill. Stewart, G. (2000). En busca del valor. Barcelona: Gestión. 